\title{
Geostatistical method to delineate anomalies of multi-scale spatial variation in hydrogeological changes due to the Chichi earthquake in the ChouShui River alluvial fan in Taiwan
}

\author{
Yun-Bin Lin · Yih-Chi Tan · Yu-Pin Lin · Chen-Wuing Liu · Chien-Jen Hung
}

\begin{abstract}
This study uses Ordinary Kriging (OK), Sequential Gaussian Simulation (SGS) and Simulated Annealing Simulation (SAS) to relocate the completely heterotopic dataset from the locations of the Standardized Satellite Oriented Control Point System (SSOCPS) stations to the Groundwater Monitoring Networks (GMNS) stations and factorial kriging to analyze and map relationships among
\end{abstract}

Received: 18 February 2004 / Accepted: 13 July 2004

Published online: 17 September 2004

(C) Springer-Verlag 2004

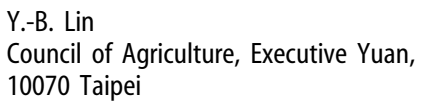

Council of Agriculture, Executive Yuan, 10070 Taipei

\section{Y.-C. Tan · C.-W. Liu}

Department of Bioenvironmental Systems Engineering, National Taiwan University, 10673 Taipei, Taiwan, R.O.C

Y.-P. Lin ( $\square)$

Department of Landscape Architecture,

Chinese Culture University, 55 Hwa-Ken Rd. Yangming Shan,

11114 Taipei, Taiwan

E-mail: yplin@faculty.pccu.edu.tw

Tel.: +886-2-28626433

Fax: $+886-2-28617507$

C.-J. Hung

Department of Civil Engineering,

Lan-Yang Institute of Technology, I-Lan,

26141, Taiwan, R.O.C.

Present address: Y.-B. Lin

Department of Bioenvironmental Systems Engineering,

National Taiwan University, 10673 Taipei,

Taiwan, R.O.C.

Present address: Y.-C. Tan

Hydrotech Research Institute, National Taiwan University,

10673 Taipei, Taiwan, R.O.C.

Present address: C.-W. Liu

Hydrotech Research Institute, National Taiwan University,

10673 Taipei, Taiwan, R.O.C. seven variables, including the hydraulic conductivities of three aquifers, the vertical displacements of the ground and groundwater level changes in the wells of three aquifers, and also to delineate the anomalies of multi-scale spatial variation of hydrogeological properties associated with the ChiChi earthquake, measuring 7.3 on the Richter scale, in the ChouShui River alluvial fan in Taiwan. In this study, the anomalies of spatial variation of hydrogeological properties associated with the earthquake are illustrated at micro, local and regional scales of 9, 12 and $36 \mathrm{~km}$, respectively. In the study area, regionalization components associated with variation at local and regional scales are obtained and mapped by factorial kriging. Factorial Kriging Analysis (FKA) also demonstrated that the main effects of the ChiChi earthquake on the spatial variations of groundwater hydrological changes include porous media compression at micro scale, hydrogeological heterogeneousness of the sediments within the aquifer at local scale and the cyclic loading of deviatoric stress at regional scale. Finally, maps of spatial variations of regional components fully depicted all of the anomalies of spatial variation of hydrogeological changes due to the ChiChi earthquake and can be used to identify, confirm and monitor the hydrogeological properties in this study area.

Keywords Earthquake Hydrogeological changes - Complete heterotopy - Geostatistics . Factorial kriging analysis $\cdot$ Spatial variation anomaly · Taiwan

\section{Introduction}

During the past few decades, identifying the hydrological changes in groundwater caused by earthquakes has 

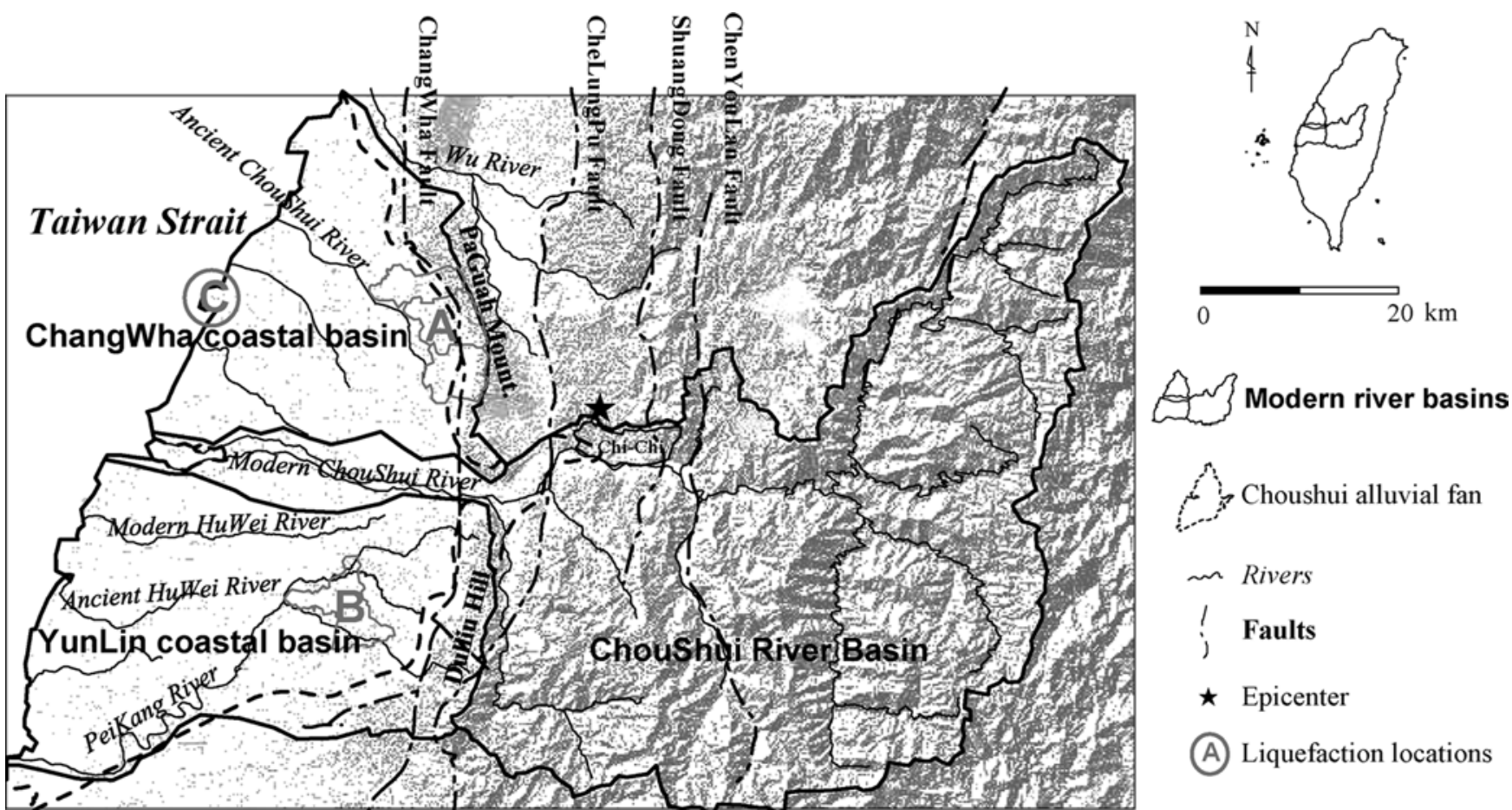

Choushui alluvial fan

m Rivers

; Faults

$\star$ Epicenter

(A) Liquefaction locations

Fig. 1

Geography and geology of the study area, including faults and epicenters

received considerable attention. Those efforts attempt to elucidate the mechanics that govern the hydrological changes in groundwater and to treat the changes that precede the earthquake as a pre-cursor of the incoming earthquakes. Numerous studies (Roeloffs 1996) have suggested that the poroelastic theorem (Biot 1956a, 1956b) can be applied to describe the relationship between the excess pore pressure and the porous media compression. Cooper and others (1965) showed that the excess pore pressure could induce groundwater level changes in the wells. They concentrated on the relationship between the compression of the porous media and the groundwater level changes in the wells, and intended to derive the crust strain from groundwater level changes in the wells using the poroelastic model (Ohno and Wakita 1997; Kunugi and others 2000). However, the insufficiency and uneven distribution of the monitoring wells makes the integrated relationship hard to establish (Roeloffs 1998). Moreover, the poroelastic model considers the crust in the vertical direction as vertically homogeneous over many kilometers, when the inhomogeneous strata of the aquifers are ignored. The disparity of scales between the model and measured data also makes the relationship uncertain (Grecksch and others 1999).

The delineations of spatially anomalous changes in groundwater levels induced by earthquakes are important in hydrogeological and geological studies for understanding and determining the mechanisms, relationships and uncertainties involved in the effect of earthquakes on groundwater or hydrogeological properties. Many researchers have reported hydrological and geochemical anomalies associated with earthquakes, but no research has focused on the spatial anomalies of multi-scale changes of groundwater levels induced by earthquakes. The latest research in this area (Montgomery and Manga 2003) implies that the mechanics of hydrological changes in groundwater are complicated. The problem of scale is important. Different mechanics govern hydrological changes in groundwater at different scales. The mechanics may include the compression of porous media and other mechanisms, such as the hydrogeological heterogeneity of the sediments within the aquifer and the cyclic loading of deviatoric stress.

At 01:47'12.6" on September 21, 1999, an earthquake of the magnitude of 7.3 on the Richter scale $\left(\mathrm{M}_{\mathrm{L}}\right)$ occurred in the middle of Taiwan, caused by the motion of the CheLungPu thrust fault (Fig. 1). The epicenter was at $23.87^{\circ} \mathrm{N}$ and $120.75^{\circ} \mathrm{E}$, near the town of ChiChi, which is around $10 \mathrm{~km}$ away from the ChouShui River alluvial fan (Ma and others 1999; Yu and others 2001). Some local but severe liquefaction occurred in the fan following the earthquake, as indicated in Fig. 1. The ChouShui River alluvial fan is in the mid-western plain of Taiwan and has an area of around $1,700 \mathrm{~km}^{2}$. The northern boundary of the fan is the $\mathrm{Wu}$ River and the southern boundary is the PeiKang River. The ChouShui River flows from east to west through two anticlines, the Dulliu Hill and PaGuah Mountain. The originally onefold ChouShui River basin is divided into three sub-basins because the embankment for flood control follows the two sides of the ChouShui River since 1911 (Fig. 1).

In 1992, the Water Resources Agency established a Groundwater Monitoring Network System (GMNS) to monitor the quality and the quantity of the groundwater and the mitigation of subsidence in Taiwan. The network in the ChouShui River alluvial fan includes 70 evenly 
(a)

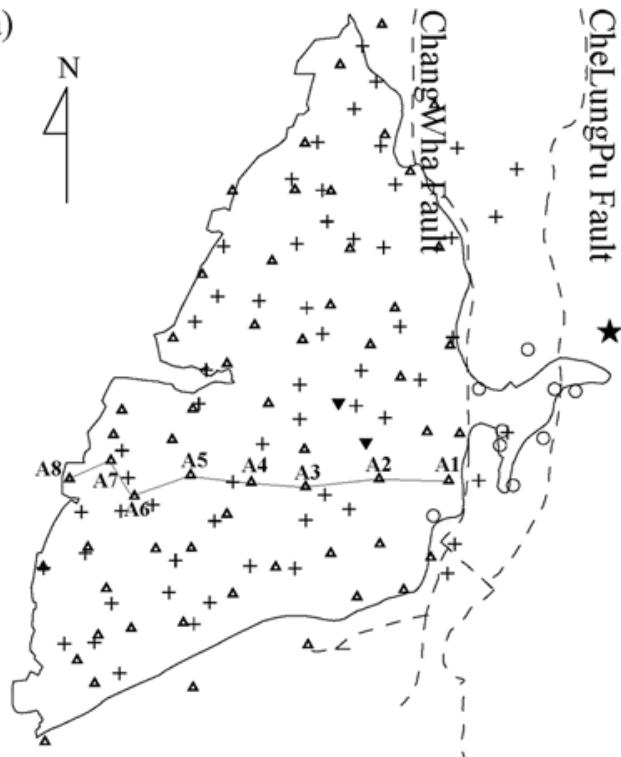

+ SSOCPS GPS control points

$\triangle$ GMNS well stations adopted in this study

GMNS well stations located in the volumetric expansion zone and not adopted in this study

$\boldsymbol{\nabla}$ Damaged well stations $\star$ Epicenter

$\Delta \Delta^{\Delta}$ Hydrogeological profile location

Fig. 2a,b

(a) GMNS and SSOCPS stations, and (b) the hydrogeological profile of the alluvial fan

distributed hydrological stations, with a total of 188 monitoring wells at various depths from 24 to $306 \mathrm{~m}$ below the surface of the ground. Each well is screened at only a single depth, and the water levels at all of the wells $(\mathrm{H})$ are automatically recorded at every hour. The hydraulic conductivity of each well $(\mathrm{K})$ is obtained by performing a pumping test (Hsu 1998). Meanwhile, in 1993, the

Department of Land Administration built a Standardized Satellite Oriented Control Point System (SSOCPS) with 59 GPS control points in the fan to measure the vertical displacements $(\Delta \mathrm{Z})$ of the ground for planning and designing the infrastructure of the basin (Fig. 2a). Various models and theorems have been proposed to explain the complicated behaviors of the groundwater level changes in the wells obtained from the GMNS records before and after the ChiChi earthquake (Chia and others 2001; Wang and others 2001; Lee and others 2002). None of them captures all of the spatial characters of groundwater level changes in all of the wells in the fan (Huang 2000; Ma and others 2001).

Kriging is a method of interpolation that provides a linear un-biased estimate at unsampled grid nodes. The method is extensively used in estimating by analyzing the spatial patterns and the variability of monitoring variables. Accompanied by multivariate statistical analysis, for example, of the covariance and the conditional probability associated with the partially heterotopic datasets, the values at unsampled grid nodes can be estimated not from a

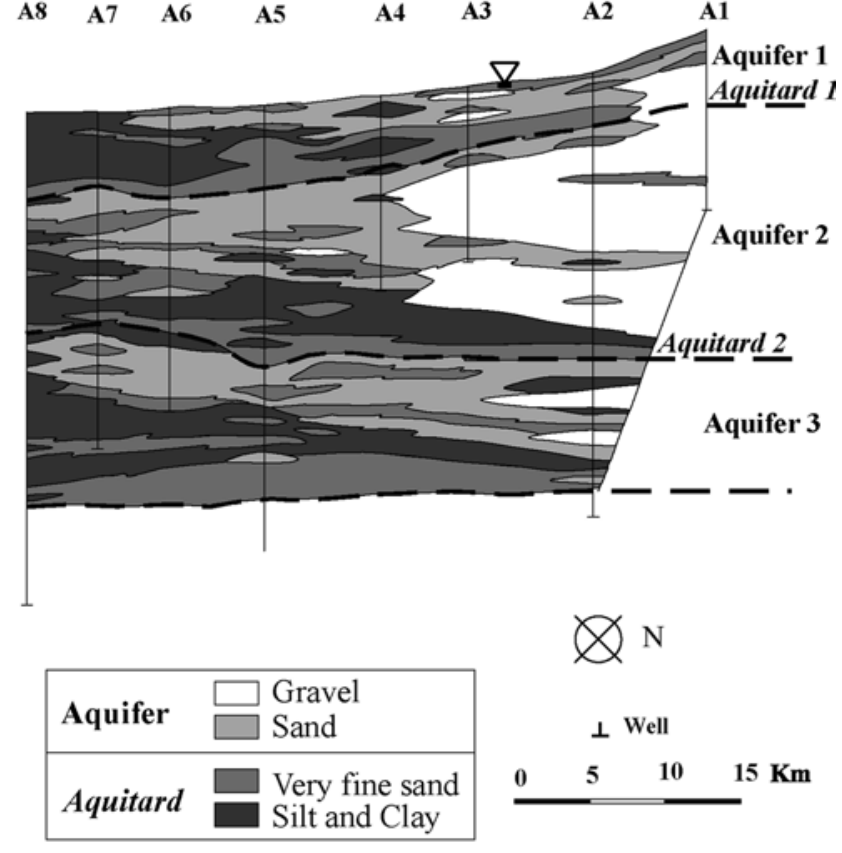

Hydrogeological profile

single variable but from all the variables involved (Odeh and others 1995; Wackernagel 1995; Goovaerts 1997). The estimates are weighted sums of the adjacent sampled variables. The weights depend on the structure of the correlation and the cross-correlation. These weights are selected by minimizing the estimation variance (Cressie 1990). Ordinary Kriging (OK) is the most commonly used algorithm that constrains the sum of the weights to unity (Isaak and Srivastava 1989). Simple Kriging (SK) is an alternative algorithm which uses a stationary mean and allows the estimate to be made with prior knowledge of the stationary mean of the variable. Recent examples include those in Almeida and Journel (1994), and Lin and others (2000a, 2000b, 2001).

Stochastic conditional simulation methods, such as Sequential Gaussian Simulation (SGS) and Simulated Annealing Simulation (SAS), can be applied to generate multiple realizations, considering the joint accuracy of the entire simulating field. They are unlike classical interpolation techniques that consider only local accuracy. The simulation methods generate a set of values with specific constraints including the mean, covariance, histogram and correlation structure of variables and also reproduce the measured data at several locations. These realizations provide a visually and quantitatively measure of spatial uncertainty (Goovaerts 1997). These methods have been recently applied in many fields (Deutsch and Cockerham 1994; Deutsch and Journel 1998). Lin and Chang (2000), and Lin and others $(2000 \mathrm{a}, 2000 \mathrm{~b}, 2001)$ applied SGS and SAS to generate multiple realizations and identify the spatial patterns of pollutants and hydraulic conductivities. 
Factorial kriging is a variant of kriging for estimating and mapping the different sources of spatial variability identified on the experimental variogram (Christakos 1984; Wackernagel 1988; Matheron 1989; Goovaerts 1997). Therefore, spatial structures of interesting variables, given by the variograms, are decomposed into various structural components. The spatial variations associated with various processes can be distinguished by Factorial Kriging Analysis (FKA), which involves three steps: Linear Model of Co-regionalization (LMC), Principal Component Analysis (PCA) and mapping (Castrignanò and others 2000). Regionalization, which is modeling of the experimental semivariogram with a linear combination of various allowable basic models, is the most important part of FKA in the univariate case while co-regionalization is the main part in the multivariate case. Because the co-regionalization matrix should be positive semi-definite (Anderson 1984), LMC (Goulard 1989) was used to minimize the weighted sum of the squared differences between the experimental and the modeled semivariograms. The resulting matrix was then applied to PCA to investigate the relationships among variables at various scales (Wackernagel and others 1989). FKA is used extensively in many fields (Sandjivy 1984; Wackernagel and others 1989; Goulard and Voltz 1992; Goovaerts and Webster 1994; Lin 2002).

The stations of the Groundwater Monitoring Network System (GMNS) do not overlap the stations of the Standardized Satellite Oriented Control Point System (SSOCPS), so the datasets collected from GMNS and SSOCPS are completely heterotopic. Hence, this study uses OK, SGS and SAS to relocate the completely heterotopic dataset, as well as factorial kriging, to analyze and map the relationships among seven variables, including the hydraulic conductivities of the three aquifers, the vertical displacements of the ground and the groundwater level changes in the wells of the three aquifers. FKA is applied to obtain the cause of the spatial variations of groundwater hydrological changes at different scales. It also delineates the anomalous multi-scale spatial variation of hydrogeological properties of the ChouShui River alluvial fan in Taiwan, following the Chichi earthquake.

\section{Materials and methods}

\section{Materials}

The ChouShui River basin was selected as the area of interest, as shown in Fig. 1, to evaluate multi-scale anomalies of spatial variations of hydrogeological changes caused by the ChiChi earthquake in central Taiwan. Figure 2 presents the sampling sites and hydrogeological profiles of the alluvial fan in the study area. Due to the influence of the global climate change on sedimentary environment, three aquifers (Aquifers 1,2 and 3), which can be identified in the analysis of the profiles (Central Geological Survey 1994, 1999). Two rapid risings of the mean sea level 10,000 years ago and 120 to 140,000 years ago in the Quaternary period generated the two muddy aquitards, Aquitards 1 and 2, respectively, embedded in the aquifers (Fig. 2b). The thickness of the gravels in the aquifer falls from the east to the west and the northwest. The pinch-out of the aquifer is under sea level and away from the west coast.

The rupturing of the CheLungPu fault during the ChiChi earthquake led to several meters of oblique thrust of the hanging wall relative to the footwall. The records of GMNS showed that the groundwater level rose in some wells from 1 to $7 \mathrm{~m}$ and fell in others from -2 to $-11 \mathrm{~m}$ following the ChiChi earthquake (Water Resources Agency 1999a, 1999b). The GPS measurements indicated only minor subsidence $(<0.5 \mathrm{~m})$ in the ChouShui River alluvial fan after the ChiChi earthquake (Department of Land Administration 2000). Negative groundwater level changes were recorded in wells in a narrow belt between the CheLungPu and ChangHwa thrust faults. This volumetric expansion zone in the footwall is perhaps associated with the dragging effect of thrusting. Besides, 162 wells that belong to 59 stations reveal rising groundwater level changes on the west side of the ChangHwa thrust fault, i.e. these wells are used in this study (Fig. 2a).

Three types of hard data are used herein to measure the spatial variations of hydrogeological changes.

1. Hydraulic conductivities $(\mathrm{K})$ were obtained by pumping tests in the wells before the earthquake. All wells were screened only at a single depth, so the hydraulic conductivity obtained from each aquifer is denoted as, for example, $\mathrm{K} 1$ for the hydraulic conductivity of the well screened at Aquifer 1 (where 1 in $\mathrm{K} 1$ indicates Aquifer 1). The scale of hydraulic conductivity is $10^{2} \mathrm{~m}$ per day (Taiwan Sugar Corporation 1997). Following Freeze (1975) and Lin and others (2000b), this study uses the $\log$ values of the hydraulic conductivities.

2. GMNS wells also record differences in groundwater levels in wells between 02:00' and 01:00' on September 21 . The groundwater level changes in the wells $(\Delta \mathrm{H})$ are indicated as, for instance, $\Delta \mathrm{H} 2$ for the well screened at Aquifer 2 (where 2 in $\Delta \mathrm{H} 2$ refers to Aquifer2).

3. The vertical ground displacements $(\Delta \mathrm{Z})$ obtained from the 59 GPS control points of SSOCPS before and after the ChiChi earthquake (positive for rising).

Table 1 provides statistical descriptions of all the hard data. $\mathrm{K} 1$ and $\Delta \mathrm{H} 1$ have large positive skewness; all data are positively skewed except for $\Delta \mathrm{Z}$. The large positive skewness indicates the looser stratum in the shallow forms numerous data of bigger $\mathrm{K} 1$ and $\Delta \mathrm{H} 1$ and makes the right tail heavier than the left tail in the histogram. The distributions of $\mathrm{K} 2$ and $\Delta \mathrm{H} 2$ are least skewed. Aquifer 3 has the fewest sample points. Not only are hard data, but also soft data (categorical data), concerning the parent soil materials of the fan, adopted. The soft data are used to relocate the completely heterotopic dataset. The parent soil materials are categorized into the slate and the mudstone mixed with the shale. The ratio of the distributed area in the ChouShui River alluvial fan is 56 to 44 (Council of Agriculture 1997; Fig. 3). 
Table 1

Descriptive statistics of original datasets

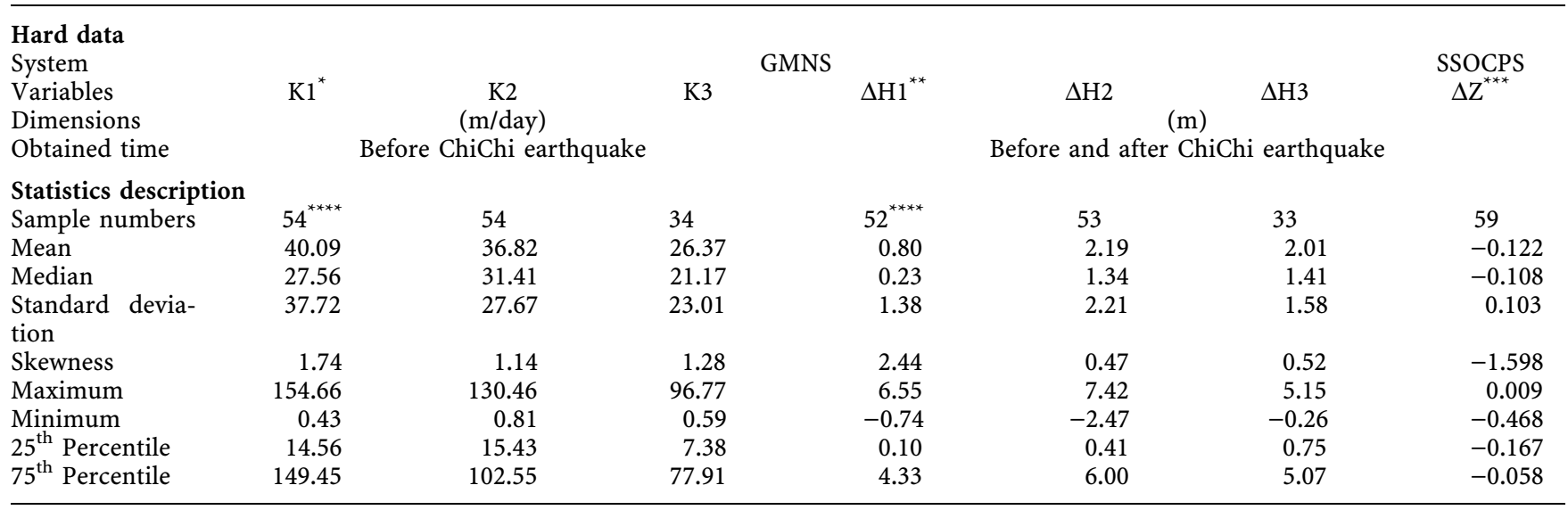

${ }^{*} \mathrm{~K} 1$ for the hydraulic conductivity of the well screened at Aquifer $1 ;{ }^{* *} \Delta \mathrm{H} 1$ for the difference of the groundwater level in wells between $01: 00$ $\mathrm{AM}$ and 02:00 AM on September 21 in Aquifer 1; ${ }^{* * *} \Delta \mathrm{Z}$ for the vertical ground displacement before and after the ChiChi earthquake; ${ }^{* * *}$ The difference is caused by the damages of the monitoring wells induced by the Chichi earthquake

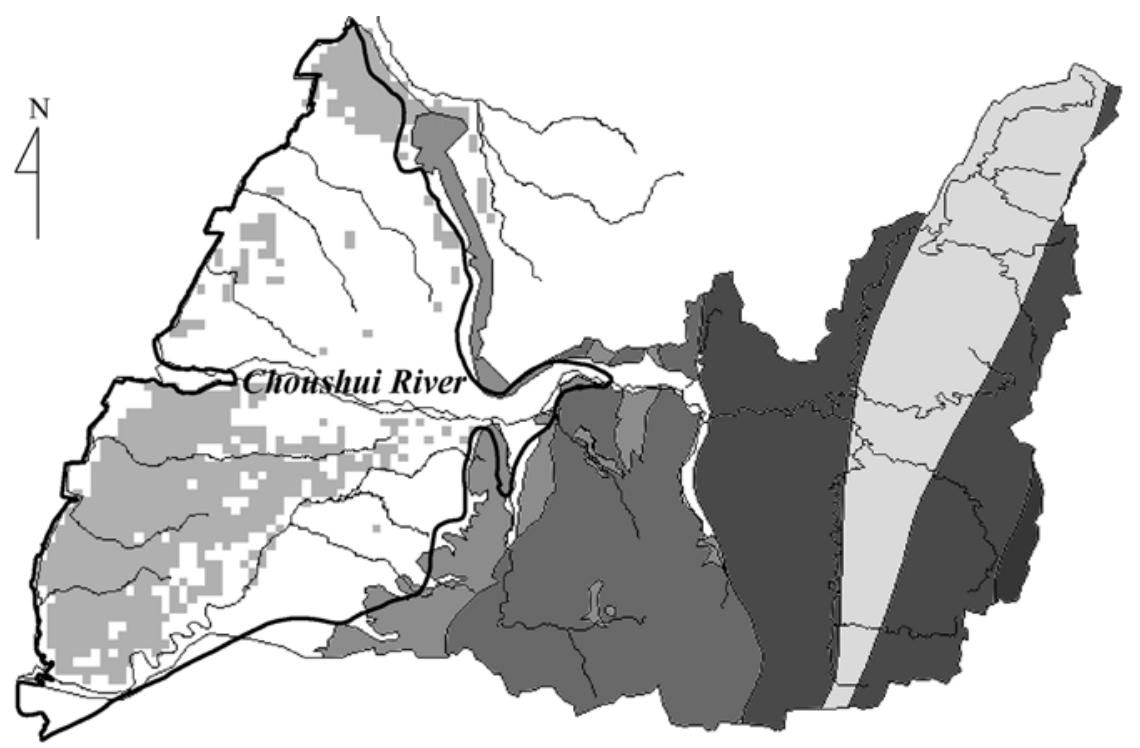

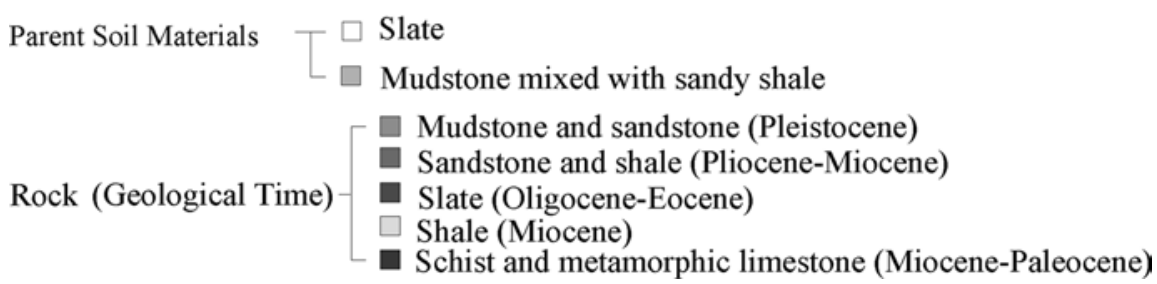

Fig. 3

Geology and soil parent materials of the alluvial fan
Table 2 presents the correlation coefficients among eight variables, including the soft data. The low correlation coefficients $(<0.472)$ may imply that the traditional correlation coefficients could not fully reveal the spatial correlations of the eight variables. The correlation coefficients of the soil parent materials and three hydraulic conductivities are all near zero. The sedimentary grain size affects the hydraulic conductivity. The sedimentary environment, such as the flow speed, affects the grain size. The zero correlation coefficient specifies that the parent soil materials which are irrelevant or insufficient for describing the hydraulic conductivity and the sedimentary environment. Furthermore, the codispersion coefficients (Wackernagel 1994, 1995) of the parent soil materials and the three hydraulic conductivities are also invariant with $h$, so the parent soil material is not brought into FKA.

\section{Methods}

In the study area, the stations of GMNS do not overlap the stations of SSOCPS, so the datasets collected from GMNS and SSOCPS are completely heterotopic. Hence, the cross covariance cannot be obtained from completely 
Table 2

Statistical descriptions and parameters of cross validation of relocations

\begin{tabular}{|c|c|c|c|}
\hline \multirow[t]{4}{*}{ Statistics } & \multicolumn{3}{|l|}{ Methods } \\
\hline & (a) & (b) & (c) \\
\hline & Univariate $\mathrm{OK}$ & Collocated OK & SGS \\
\hline & \multicolumn{3}{|c|}{ The difference of the measured and the estimated $\Delta \mathrm{Z}(\mathrm{m})$} \\
\hline Mean & 0.006 & 0.002 & 0.013 \\
\hline Maximum & 0.179 & 0.180 & 0.270 \\
\hline Minimum & -0.182 & -0.176 & -0.118 \\
\hline Standard deviation & 0.075 & 0.077 & 0.078 \\
\hline \multirow[t]{2}{*}{ Skewness } & -0.207 & -0.068 & 1.215 \\
\hline & \multicolumn{3}{|c|}{ Cross-validation parameters } \\
\hline KME & 0.049 & 0.019 & -0.022 \\
\hline $\begin{array}{l}\text { MSSE } \text { (The tolerance }= \\
0.368)\end{array}$ & 0.790 & 0.920 & 1.077 \\
\hline
\end{tabular}

heterotopic datasets. This study, for the first time, incorporates the generally distributed soft data concerning parent soil materials to relocate a completely heterotopic dataset without destroying the spatial structure. Three methods, including OK, SGS and SAS were used to relocate the vertical displacements of the ground at the SSOCPS stations to the GMNS stations. The crosscovariance of the relocated dataset from SSOCPS and the datasets obtained from GMNS was then determined to describe the spatial relationships among all variables. FKA was used in this study to explore the effect of the problem of scale on the hydrogeological spatial variation anomalies caused by the earthquake. The flow chart in Fig. 4 indicates the procedure used. Three methods were applied to relocate SSOCPS data to the GMNS stations. Then, all the GMNS datasets and the relocated SSOCPS datasets are grouped as Dataset \#1 and Dataset \#2. Dataset \#1 is a blank dataset, and includes all records of K1, K2 and K3, and Dataset \#2 is the experimental dataset, and includes all records of $\mathrm{K} 1$, $\mathrm{K} 2, \mathrm{~K} 3, \Delta \mathrm{H} 1, \Delta \mathrm{H} 2, \Delta \mathrm{H} 3$ and $\Delta \mathrm{Z}$, to identify the effects of the extra information provided by the ChiChi earthquake on the analysis of hydraulic conductivity after the ChiChi earthquake. Factorial kriging analysis also identifies the multi-scale spatial variation of the hydrogeological changes.

\section{Variography}

The most important part of FKA is evaluating the regionalized factors. The scales must be decided before the allowable basic models can be linearly combined; then, the regionalized factors can be determined. The modeling of the experimental semivariogram is purely mathematical; the physical meanings of the decision concerning the scales follow from physical knowledge of the natural mechanics in the study area before the operation (Goovaerts 1997).

In the first step of variography, data obtained before and after the ChiChi earthquake in the ChouShui River alluvial fan were initially divided horizontally into the minor, the local and the regional scales. Based on the Nyquist sampling theorem (Korner 1988), the sampling rate must be at least double the highest frequency in the sample to enable the original signal to be reconstructed. The stations networks can identify the phenomenon with a resolution of $2 \bar{h}$ only if the average distance between the stations is $\bar{h}$

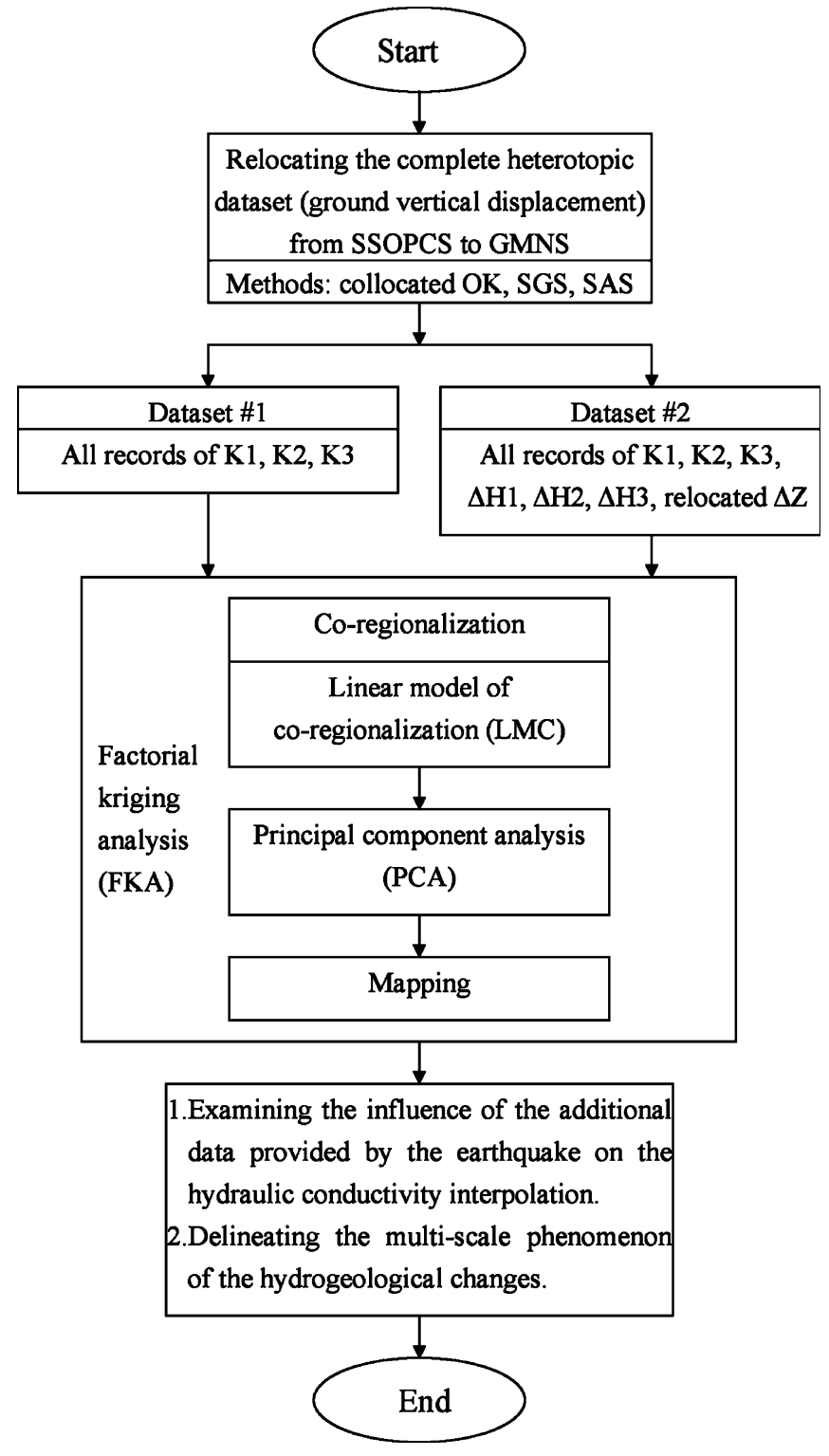

Fig. 4

Flow chart

around $4.5 \mathrm{~km}$ herein. Hence, the minor scale is set to $9 \mathrm{~km}$. The longest west-east dimension of the study area is around $40 \mathrm{~km}$, which is approximately two thirds of the 
north-south dimension. The groundwater level changes rise from the wells in the east toward those in the middle of the fan, falling toward the west (Chia and others 2001; Wang and others 2001; Lee and others 2002). The relationship between the easternmost and the westernmost changes need to be examined, so the regional scale is therefore set to $36 \mathrm{~km}$ in the study. The local scale should be between the minor and the regional scale. The range of liquefaction due to the ChiChi earthquake was considered to yield a local scale of $12 \mathrm{~km}$. Meanwhile, the software VARIOWIN (Yvan 1996) is used to model the experimental semivariogram.

\section{Cross validation}

The modeling of the experimental semivariogram is inevitably subjective (Woodbury and Sudicky 1991), so cross validation is applied to evaluate the fitting of the semivariogram. The Indicative Goodness of Fit (IGF) proposed in the VARIOWIN is applied to determine the modeled semivariogram that best fits the experimental semivariogram. The Mean Square Standard Error (MSSE) and the Kriging Mean Error (KME) are utilized in the evaluation, and these values approach zero and one, respectively. They are defined as

$\mathrm{KME}=\frac{1}{n} \sum_{i=1}^{n}\left(Z_{i}^{*}-Z_{i}\right)$

$\operatorname{MSSE}=\frac{1}{n} \sum_{i=1}^{n} \frac{\left(Z_{i}^{*}-Z_{i}\right)^{2}}{\sigma_{i}^{2}}$

where $Z_{i}$ is the measured value; $Z_{i}^{*}$ is the estimated value; $\sigma_{i}^{2}$ is the kriging variance, and $n$ is the number of the stations. The tolerance of MSSE is set to $\pm 2 \sqrt{2 / n}$ (Chilès and Delfiner 1999).

\section{Ordinary kriging}

In OK, two algorithms were examined to determine whether the soft data could be adopted. They are (1) univariate $\mathrm{OK}$ with $\Delta \mathrm{Z}$, and (2) bivariate $\mathrm{OK}$ with both $\Delta \mathrm{Z}$ and soft data. Data on the parent soil material are selected as soft data, so the amount of soft data greatly exceeds the amount of main variables. When the value of any grid node is estimated, the vast amount of effects of the soft data near the grid node can be screened by the effect of the collocated soft datum at the grid node. The soft data near the grid are therefore excluded and the collocated datum is retained in the calculation to prevent the numerical instability in the performance. If the soft data are adopted, then the LMC should be applied in collocated OK to ensure the positive semi-definiteness of the co-regionalization matrix.

\section{Sequential Gaussian simulation}

The first necessary condition for SGS is that the main variable follows a univariate normal distribution, so $Y$ is the normal score transformation of $\Delta \mathrm{Z}$. The value $Y$ at $u$ and $u+h$ necessarily follows a bivariate normal distribution (Deutsch and Journel 1998). The covariance $C_{\gamma}(h)$ of $Y(u)$ and $Y(u+h)$ is

$$
\begin{aligned}
G\left(h ; y_{p}\right) & =\operatorname{Prob}\left(Y(u) \leqslant y_{p}, Y(u+h) \leqslant y_{p}\right) \\
& =p^{2}+\frac{1}{2 \pi} \int_{0}^{\sin ^{-1}\left(C_{Y}(h)\right)} \exp \left(-\frac{y_{p}^{2}}{1+\sin \theta}\right) d \theta
\end{aligned}
$$

where the probability (Prob) that $Y$ is under $y_{p}$ is $p$, and the theoretical index semivariogram $\gamma_{I}\left(h ; Y \leq y_{p}\right)$ can be expressed as $\gamma_{I}\left(h ; Y \leq y_{p}\right)=p-G\left(h ; y_{p}\right)$.

Once the univariate and the bivariate normal tests have been passed, the normal score transformation of the original data are required to generate a random field with a Gaussian distribution in SGS. The conditional distribution function is then established by kriging at the un-sampled grid node.

Add a simulated value from the conditional distribution at random to the dataset. The values at the other unsampled grid nodes are simulated in sequence with the original field data and the formerly obtained data (Deutsch and Journel 1998). The program SGSIM of GSLIB is used to determine the mean of ten simulations (Deutsch and Journel 1998). With regard to soft data in the program SGSIM, the correlation between the main variable and the auxiliary variable, which is a soft data variable, is only considered if the main and auxiliary variables are collocated. The assumption is called the Markov-Bayes model (Almeida and Journal 1994; Goovaerts 1997). The prior decision regarding the stationary mean of the Gaussian distribution requires that SK, rather than OK, be used in SGS.

\section{Simulated annealing simulation}

SAS begins with an initially realized dataset that is generated from the histogram of the original SSOCPS data. Sequentially swapping the values associated with two randomly selected grid nodes perturbs the realization. The perturbation is accepted if the swapping reduces the objective function, the weighted sum associated with the histogram, the semivariogram and the correlation coefficient (Deutsch and Journel 1998). The parameter, temperature, of the Boltzman distribution is used to prevent a local optimum from being attained. A perturbation can be rejected even if the swapping reduces the objective function. The probability of the rejection is lower when the temperature is higher (Goovaerts 1997; Lin and Chang 2000). The program SASIM of GSLIB is used to perform the simulation, and the modeled semivariogram of SAS continues using the one in collocated OK. The simulated results of the program SAMSIM are then post-processed using the program ANNEAL of GSLIB to conform to an image that already has the desired spatial features (Deutsch and Journel 1998). The former SGS result is used as the training image.

\section{Factorial kriging analysis}

The direct and the cross experimental semivariograms of the variables, $\Gamma(h)=\left[\gamma_{i j}(h)\right]$, can be fitted with a linear combination of various basic allowable models at various scales of $I$, given by $g^{\prime}(h)$. The co-regionalization method is expressed as

$\Gamma(h)=\left[\gamma_{i j}(h)\right]=\sum_{l} \mathbf{B}^{l} g^{l}(h)$ 
where $\mathbf{B}^{l}$ must be a positive semi-definite matrix. Goulard (1989) proposed the minimization of the squared difference between the experimental and the modeled values in semivariograms to determine the positive semi-definite coregionalization matrix. Goulard and Voltz (1992) later suggested that the Weighted Sum of Squares (WSS) be optimally adopted. WSS may yield a deviation in the modeling of the direct semivariogram, so the result of the modeling should be visually checked (Goovaerts 1997). In FKA, variable $X_{i}$ is the linear combination of the $k$ th regionalized factor $W_{k}^{l}(u)$ at a scale of $I$. It can be expressed as

$X_{i}(u)=\sum_{l} X_{i}^{l}(u)=\sum_{l} \sum_{k} a_{i k}^{l} W_{k}^{l}(u)$

where $\mathbf{a}^{l} \mathbf{a}^{l T}=\mathbf{B}^{l}=\mathbf{Q}^{l} \Lambda^{l} \mathbf{Q}^{l T}$; matrix $\mathbf{Q}^{l}$ consists of the orthogonal eigenvector of $\mathbf{B}^{l}$ in column; $\Lambda^{l}$ is a diagonal matrix of eigenvalues of $\mathbf{B}^{l}$, and $\mathbf{a}^{l}=\mathbf{Q}^{l} \Lambda^{l 1 / 2}$. PCA depicts the values in the first and second columns, PC1 and PC2, of the calculated $\mathrm{a}^{l}$ in the correlation circle against the $\mathrm{x}$ axis and the $y$-axis, and the relationship between the variables is identified by the position in the correlation circle (Wackernagel 1995).

The aim of the mapping step is to yield the regionalized factor $W_{k}^{l}(u)$ by co-kriging; the result is further multiplied by $a_{i k}^{l}$ to yield the scalar component $X_{i}^{l}(u)$ at grid nodes.

\section{Results and discussion}

\section{Multi-scale analysis}

In regionalization, choosing the models for fitting is analogous to the guessing of the causes of the recorded phenomenon in different scales (Castrignanò and others 2000). Selecting allowable models for fitting basically depend on the shape of the experimental semivariogram when the causes of the recorded phenomenon are unknown. The best-fit variogram and cross-variogram models of Datasets \#1 and \#2, are specified as the sum of three structures by a nugget effect term, a spherical model and a Gaussian model, in Eqs. (5a) and (5b), respectively, with ranges $a$ of 12 and $36 \mathrm{~km}$ at local and regional spatial scales, respectively.

$\gamma(|h|)=\left\{\begin{array}{l}1.5 \frac{|h|}{a}-0.5\left(\frac{|h|}{a}\right)^{3} \text { if }|h| \leqslant a \\ 1 \quad \text { otherwise }\end{array}\right.$

$\gamma(|h|)=1-e^{-\frac{3|h|^{2}}{a^{2}}}$

According to Goulard and Voltz (1992), the PCA result of the fitted co-regionalization matrix can be applied to determine the number of scales. If the calculated correlation is the same at two scales, then the number of models required for fitting should be reduced to one. Later PCA results will indicate that the nested model that includes three models with dissimilar ranges is rudimentary, because the correlations among the variables at the three scales vary markedly. That is, three causes jointly affect the final hydrological changes in groundwater; and the ranges of influence are all dissimilar.

\section{Cross validation}

Table $3 \mathrm{a}$ and $\mathrm{b}$ show the cross validation results of univariate $\mathrm{OK}$ and collocated $\mathrm{OK}$, respectively. Because the KME and MSSE of collocated OK are closer to zero and one, respectively, than those of univariate $\mathrm{OK}$, collocated OK yields better results and the soft data are adopted in this study. Considering the positive semidefiniteness of the co-regionalization matrix in collocated OK, LMC prevents the over fitting that may accompany univariate $\mathrm{OK}$ fitting. Also, the extra information included in the soft data improves the cross validation. Table $3 \mathrm{c}$ shows a statistical description of the cross validation of the modeled semivariogram in SGS. The statistical description is similar to that of the collocated OK result. The negative skewness of the field data positively skews the error in the estimation based on the assumption of a Gaussian distribution.

Table 3

Correlation coefficients of variables

\begin{tabular}{|c|c|c|c|c|c|c|c|c|c|c|c|}
\hline & & & & & & & & Relocated & & & \multirow[b]{2}{*}{$\begin{array}{l}\text { Soil parent } \\
\text { materials }\end{array}$} \\
\hline \multirow{11}{*}{$\begin{array}{l}\text { Relocated } \\
\Delta \mathrm{Z}\end{array}$} & & K1 & $\mathrm{K} 2$ & $\mathrm{~K} 3$ & $\Delta \mathrm{H} 1$ & $\Delta \mathrm{H} 2$ & $\Delta \mathrm{H} 3$ & $\begin{array}{l}\text { collocated } \\
\text { OK }\end{array}$ & SGS & SAS & \\
\hline & K1 & 1 & & & & & & & & & \\
\hline & K2 & 0.383 & 1 & & & & & & & & \\
\hline & K3 & 0.428 & 0.233 & 1 & & & & & & & \\
\hline & $\Delta \mathrm{H} 1$ & 0.170 & 0.197 & 0.451 & 1 & & & & & & \\
\hline & $\Delta \mathrm{H} 2$ & 0.161 & 0.197 & 0.146 & 0.472 & 1 & & & & & \\
\hline & $\Delta \mathrm{H} 3$ & 0.481 & 0.234 & 0.514 & 0.431 & 0.457 & 1 & & & & \\
\hline & $\begin{array}{c}\text { collocated } \\
\text { OK }\end{array}$ & -0.216 & -0.237 & -0.117 & -0.049 & 0.185 & 0.153 & 1 & & & \\
\hline & SGS & -0.153 & -0.185 & -0.152 & -0.107 & 0.157 & 0.170 & & 1 & & \\
\hline & SAS & -0.219 & -0.174 & -0.191 & -0.076 & 0.133 & 0.047 & & & 1 & \\
\hline & $\begin{array}{l}\text { Soil parent } \\
\text { materials }\end{array}$ & -0.023 & 0.026 & -0.064 & 0.190 & 0.168 & 0.283 & 0.231 & 0.293 & 0.278 & 1 \\
\hline
\end{tabular}




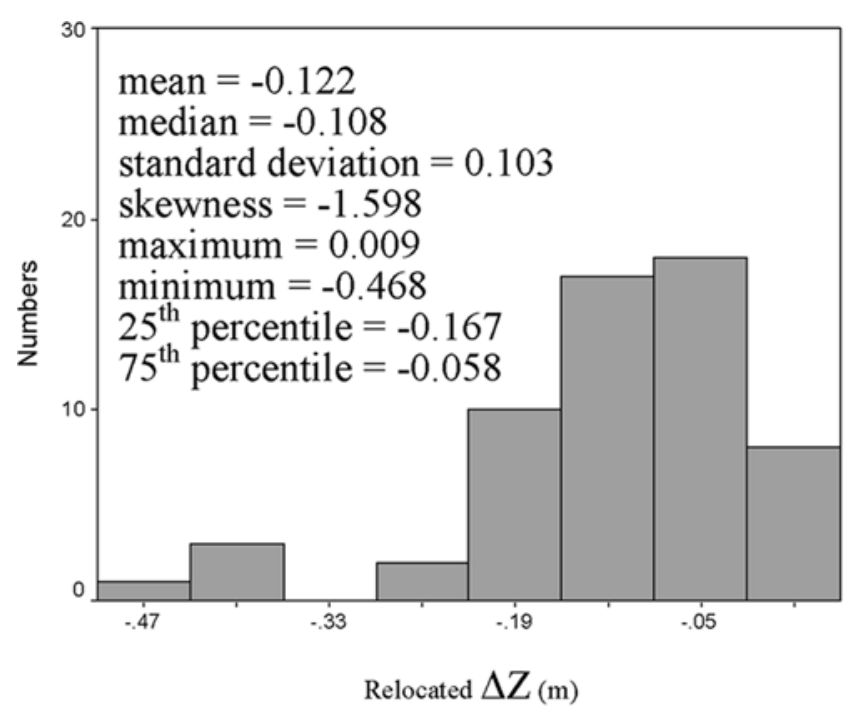

(a)

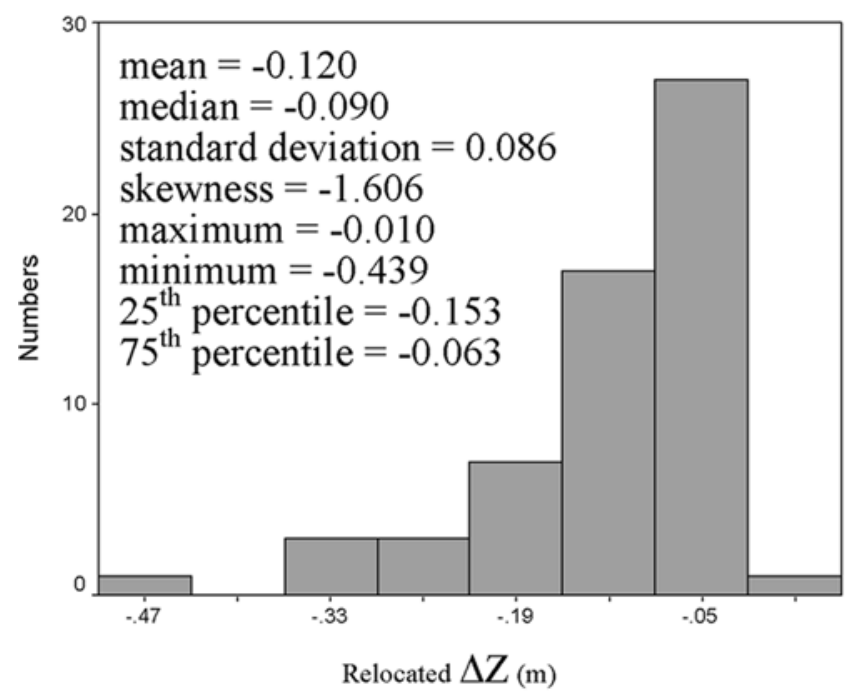

(b)

Fig. 5a-d

Histogram and statistics of (a) the measured $\Delta \mathrm{Z}$, and $\Delta \mathrm{Z}$ relocated by (b) collocated OK, (c) SGS and (d) SAS

\section{Comparisons of relocated vertical displacements}

Kriging generally estimates the value at the unsampled grid nodes from the spatial structure, the semivariogram, of the original dataset. The estimated values are always somewhat smoothed. In this study, the measured data, $\Delta \mathrm{Z}$, are relocated from the SSOCPS stations to the GMNS stations to solve the problem of complete heterotopy. The GMNS and SSOCPS both include 59 stations, all of which are evenly distributed across the ChouShui River alluvial fan. The SSOCPS station is weighted most heavily in the kriging estimation at the GMNS station when the stations are closest to each other. Hence, the $\Delta \mathrm{Z}$ can be relocated the SSOCPS stations to the GMNS stations without loss of the resolution and the spatial structure.

Figure 5 shows statistical statements of the results after collocated OK, SGS and SAS have been used to perform the

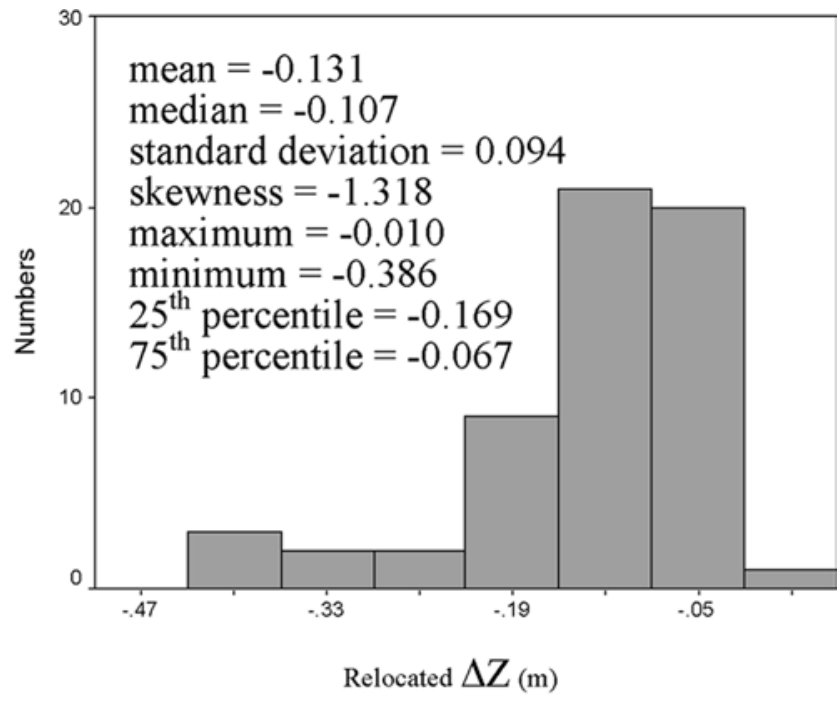

(c)

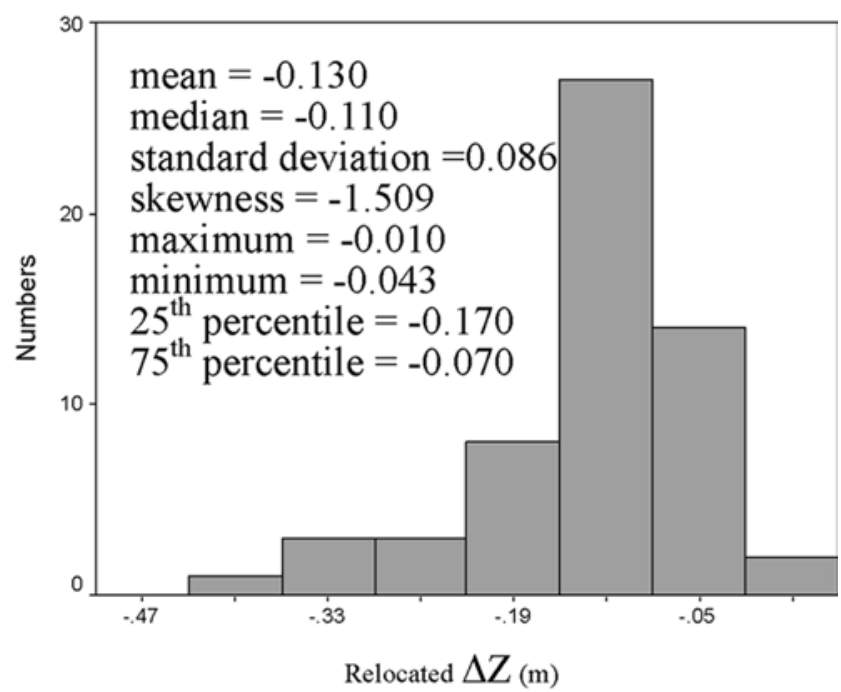

(d)

relocations. The histogram of the $\Delta \mathrm{Z}$ relocated by SGS (Fig. 5c) is almost identical to the histogram of measured $\Delta \mathrm{Z}$ (Fig. 5a). The simulation algorithms, SAS and SGS, are unlike the collocated $\mathrm{OK}$ algorithm, in that they consider not only the kriging mean but also the local variation of the unsampled grid node while estimating. According to Lin and others (2000a), SGS is better suited to estimations that involve greater local heterogeneity, as in this study. The spatial structures of the relocated datasets are also investigated with reference to the experimental semivariograms, as depicted in Fig. 6. The correlation coefficients of $\Delta \mathrm{Z}$ and the soft data are 0.29 for the original data, 0.23 for collocated OK, 0.29 for SGS and 0.28 for SAS. SGS yields the best result, so the relocation result of SGS is considered in FKA, as shown in Figs. 5 and 6. The bivariate normal test implies that the deviation is greater when the semivariogram associated with larger $\Delta \mathrm{Z}$ is fit. Hence, large $\Delta \mathrm{Z}$ is more closely connected with each other in the space and the distributed pattern is not consistent with the destructuration effect associated with the Gaussian model. 


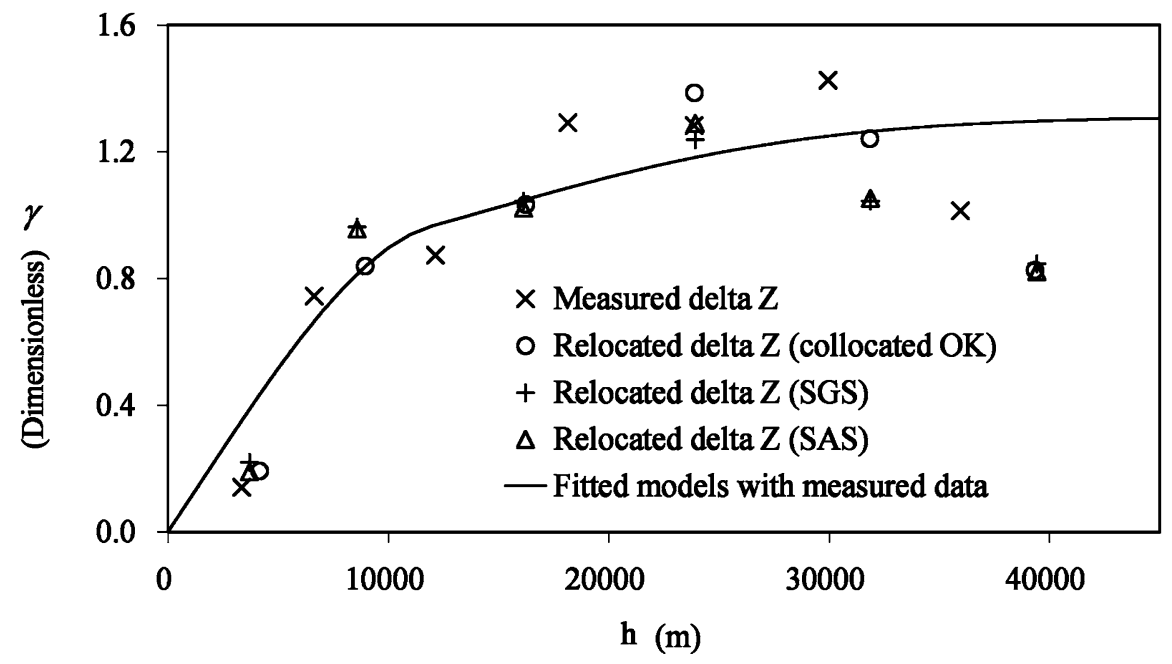

Fig. 6

Comparison of experimental semivariograms (symbol marked) of the relocated and the measured $\Delta \mathrm{Z}$ with the modeled semivariogram (solid line) of the measured $\Delta \mathrm{Z}$
The distribution of the large vertical displacements of the ground in the south-eastern part of the fan is mapped.

\section{Principal component analysis}

LMC should be performed before PCA. The variables are all normalized to zero mean and unit variance to prevent large values from over-influencing the results. Figure 7 plots the LMC result for Dataset \#1. Figure 8 shows the results for Dataset \#2 obtained by SGS; only direct semivariograms are presented to save space. No obvious deviation of the modeled from the experimental values in the direct and cross semivariogram models can be visually identified. Most direct and cross semivariogram models with low nugget effect and represent well spatial structure among the variables. These variography results verified that the traditional correlation coefficient could not fully identify the correlations among the variables in space. The PCA results at various scales show variant correlations among variables. The causes of hydrogeological changes can be investigated by considering the positions of the variables in the correlation circles and identified later on maps of regionalized factors.

Dataset \#1

Figure 9 plots the correlation circles of Dataset \#1. The percentage of the variation is $16 \%$ at micro scale, $29 \%$ at local scale and $55 \%$ at regional scale. The first two principal axes at three scales represent variations of almost $100 \%$.

At micro scale, the first principal component (PC1) is positively correlated with $\mathrm{K} 3$, and negatively with $\mathrm{K} 1$ and $\mathrm{K} 2$. However, PC1 is assumed to represent spatial discontinuity, and forms $\mathrm{K} 1$ and $\mathrm{K} 2$ as a group. K3 is separated because it has fewer (34) wells than K1 and K2 (which both have 54). At local scale, K1 dominates PC1 and $\mathrm{K} 2$ dominates the second principal component (PC2). At regional scale, $\mathrm{K} 1, \mathrm{~K} 2$ and $\mathrm{K} 3$ are strongly positively correlated with $\mathrm{PC} 1$, therefore explaining $91 \%$ of the variation. $\mathrm{PC} 1$ is presumed to correlate to the properties of the sediments in all aquifers in the ChouShui River basin. The properties of the sediments at regional scale are affected mainly by the course of the river in the alluvial fan. PC2 represents a minor variation of $9 \%$. $\mathrm{K} 1$ and $\mathrm{K} 3$ are classified in a single group and $\mathrm{K} 2$ is isolated at regional scale. PC2 is presumed to correlate to the effect of the global mean sea level. Although the three aquifers all formed from sediments of the continental facies based upon an earlier geological survey, Aquifer 2 was formed during the Last Glaciation when the global mean sea level was the lowest level of the water in any of the three aquifers in the study area. Additionally, the coastline is, in fact, the boundary of the coarse sediments transported by the river. The sediment deposited under the coastline is finer while that laid above the coastline is coarser. The interface between the sands and the gravels in the aquifer indicates the global mean sea level. The interface in Aquifer 2 is farthest from the upper fan, which is the evidence of the lowest global mean sea level. PC2 therefore represents the effects of the global mean sea level on the sedimentary environment. The mapping can substantiate the claim of the representation of the two principal axes.

\section{Dataset \#2}

Figure 10 plots the correlation circles of Dataset \#2. The first two principal axes represent over $85 \%$ variations, except at local scale. The variations are caused by the presence of more factors at local scale and the first two principal axes represent a variation of only $61 \%$. At micro scale, $\mathrm{PC} 1$ is strongly positively correlated with $\mathrm{K} 3$ and $\Delta \mathrm{H} 3$, and negatively with $\mathrm{K} 2$, as shown in Fig. 10a. The relationships $\mathrm{K} 2-\mathrm{K} 3$ and $\mathrm{K} 2-\Delta \mathrm{H} 3$ are revealed by $\mathrm{PC} 1$ to explain $62 \%$ variations. PC2 is strongly positively correlated with $\Delta \mathrm{Z}$ and negatively correlated with $\Delta \mathrm{H} 1, \Delta \mathrm{H} 2$ and $\mathrm{K} 1$. The relationships $\Delta \mathrm{Z}-\Delta \mathrm{H} 1, \Delta \mathrm{Z}-\Delta \mathrm{H} 2$ and $\Delta \mathrm{Z}-\mathrm{K} 1$ are revealed by PC2 to explain $37 \%$ variations. These PCA results show that the faulting of the ChiChi earthquake generated a wave that propagated from the deep epicenter. The greatest disturbance of energy occurred in the deepest Aquifer 3. PC1 represents the vertical flow at micro scale from Aquifer 3 to Aquifer 2. These phenomena may be explained by the fact that if $\mathrm{K} 3$, the hydraulic conductivity 

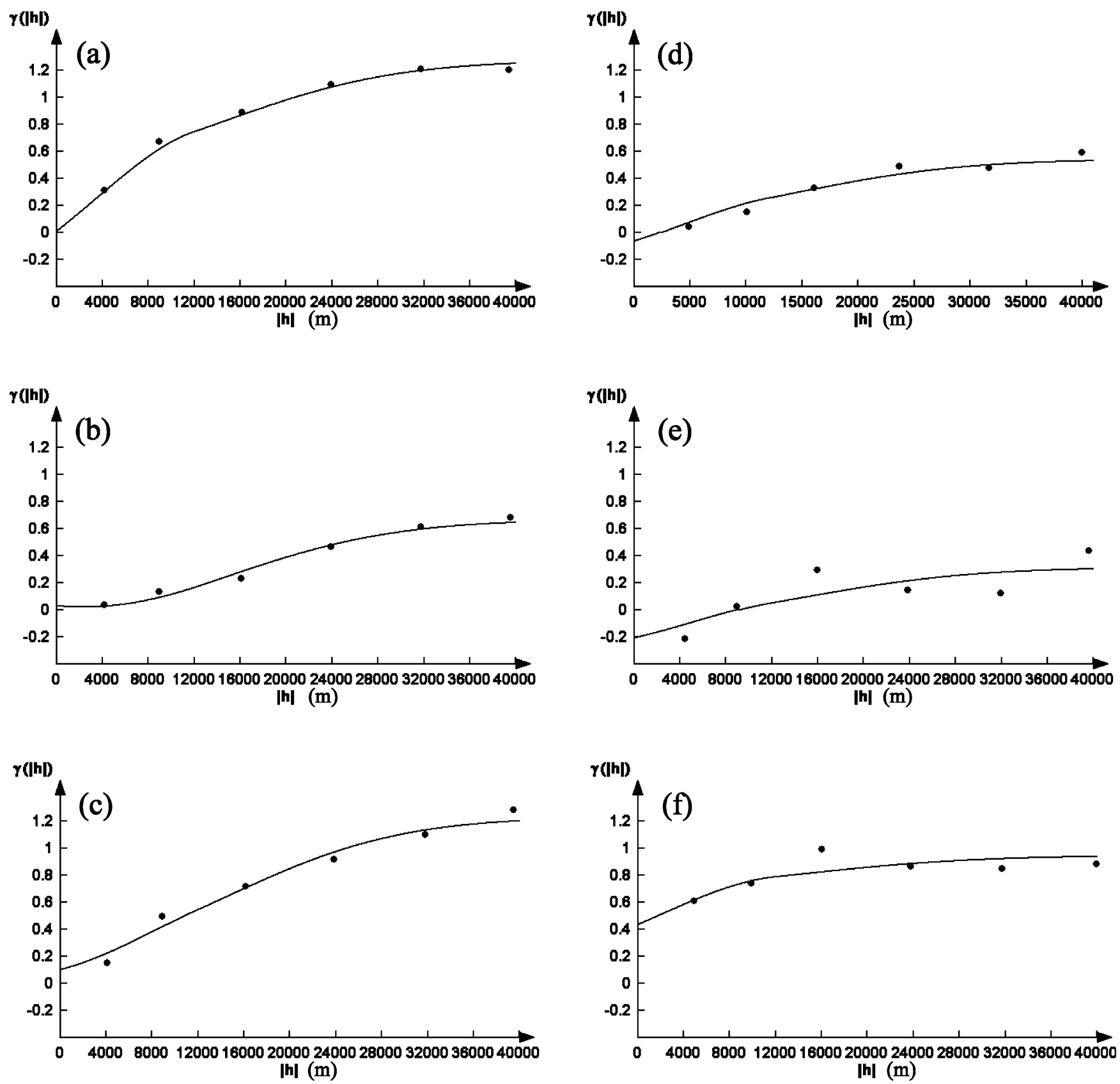

Fig. 7a-e

Experimental semivariogram (solid circle) and linear model of co-regionalization (solid line) of (a) K1, (b) K1-K2, (c) K2, (d) K1-K3, (e) K2-K3 and (f) K3, for Dataset \#1

of Aquifer 3, is high at a particular grid node, then the excess pore pressure in the aquifer will be released at the grid node, causing a sudden rise in $\Delta \mathrm{H} 3$. Additionally, if the hydraulic conductivity $\mathrm{K} 2$ above $\mathrm{K} 3$ is small at this time, then the suddenly rising $\Delta \mathrm{H} 3$ cannot easily drain out vertically. PC2 refers to a phenomenon to which Biot's poroelastic model is often applied. That is, $\Delta \mathrm{Z}$ can be determined from $\Delta \mathrm{H}$ by the deterministic description of $\Delta \mathrm{Z}-\Delta \mathrm{H}$ in shallow strata, which can be evaluated using the diffusion equation in Biot's poroelastic model. $\mathrm{K}$ is the model parameter that represents the rate of diffusion in the diffusion equation, as shown in Biot's poroelastic

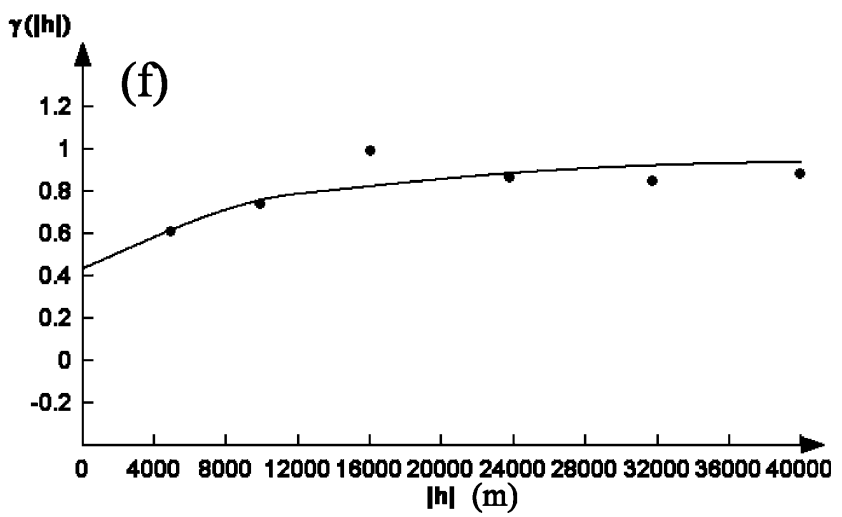

model. The PC1 and PC2 represent the vertical flows by relationships of $\Delta \mathrm{H} 3-\mathrm{K} 2$ and $\Delta \mathrm{H} 2-\mathrm{K} 1$, respectively and illustrate that sand may boil from the deepest strata to the free groundwater surface at micro scale.

At local scale, PC1 is strongly positively correlated with $\Delta \mathrm{Z}$. The other variables are aligned on both sides of PC2, as shown in Fig. 10b, indicating that $\Delta \mathrm{Z}$ does not relate to any other variables at regional scale. The relationship $\mathrm{K} 3-\Delta \mathrm{H} 3$, identified by PC2, is presumed to be as described by Lin and others (2004). That is, the heterogeneity of the hydrogeological structure is mainly responsible for groundwater level changes in the wells at local scale. In the study area, the Chichi earthquake generated the wave that propagated from east to west. The inertial effect of the fluid that flows from the upper fan to the pinch-out of the aquifer is important to exchange of momentum. 

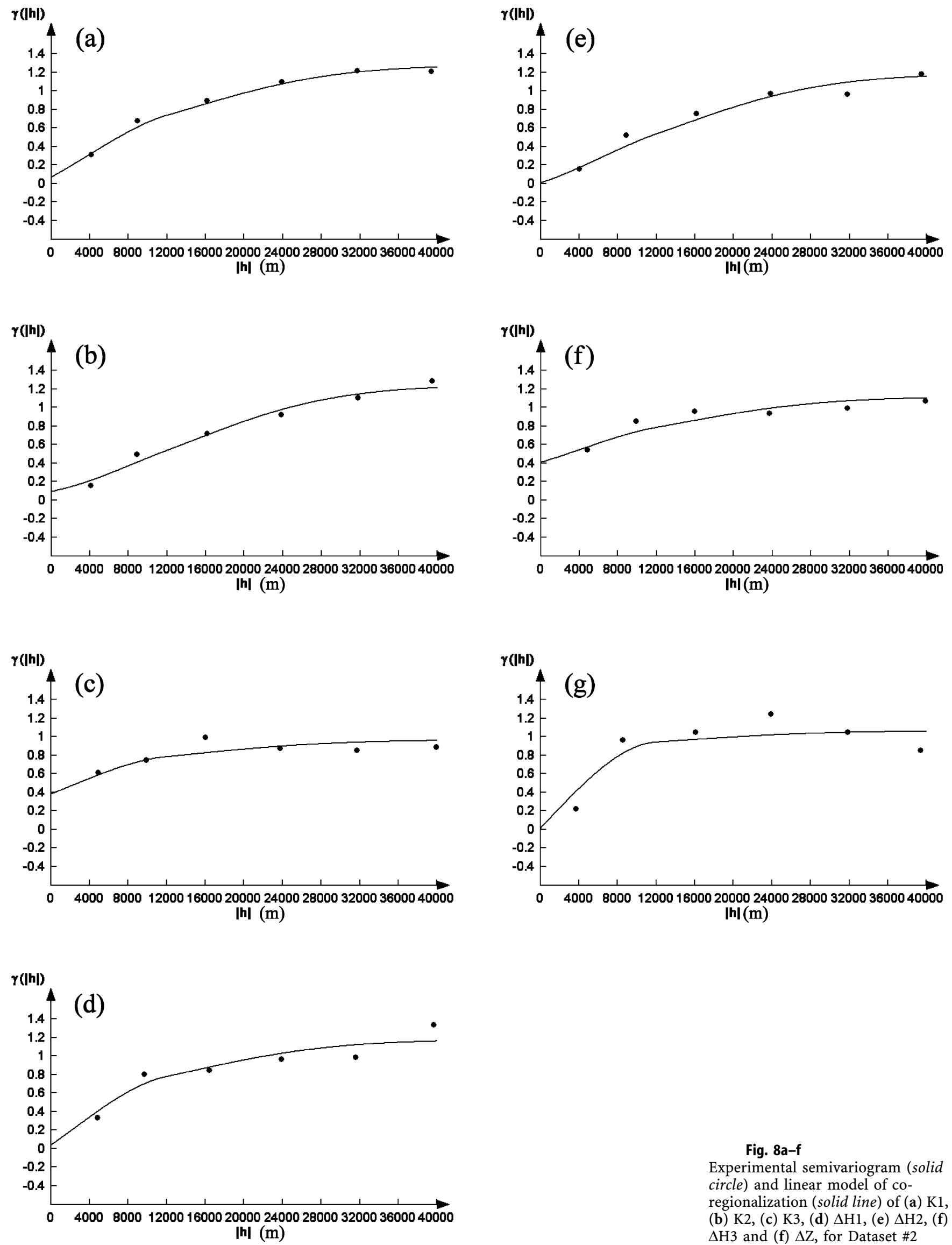

Fig. 8a-f

Experimental semivariogram (solid circle) and linear model of coregionalization (solid line) of (a) K1, (b) K2, (c) K3, (d) $\Delta \mathrm{H} 1$, (e) $\Delta \mathrm{H} 2$, (f) $\Delta \mathrm{H} 3$ and (f) $\Delta \mathrm{Z}$, for Dataset \#2 

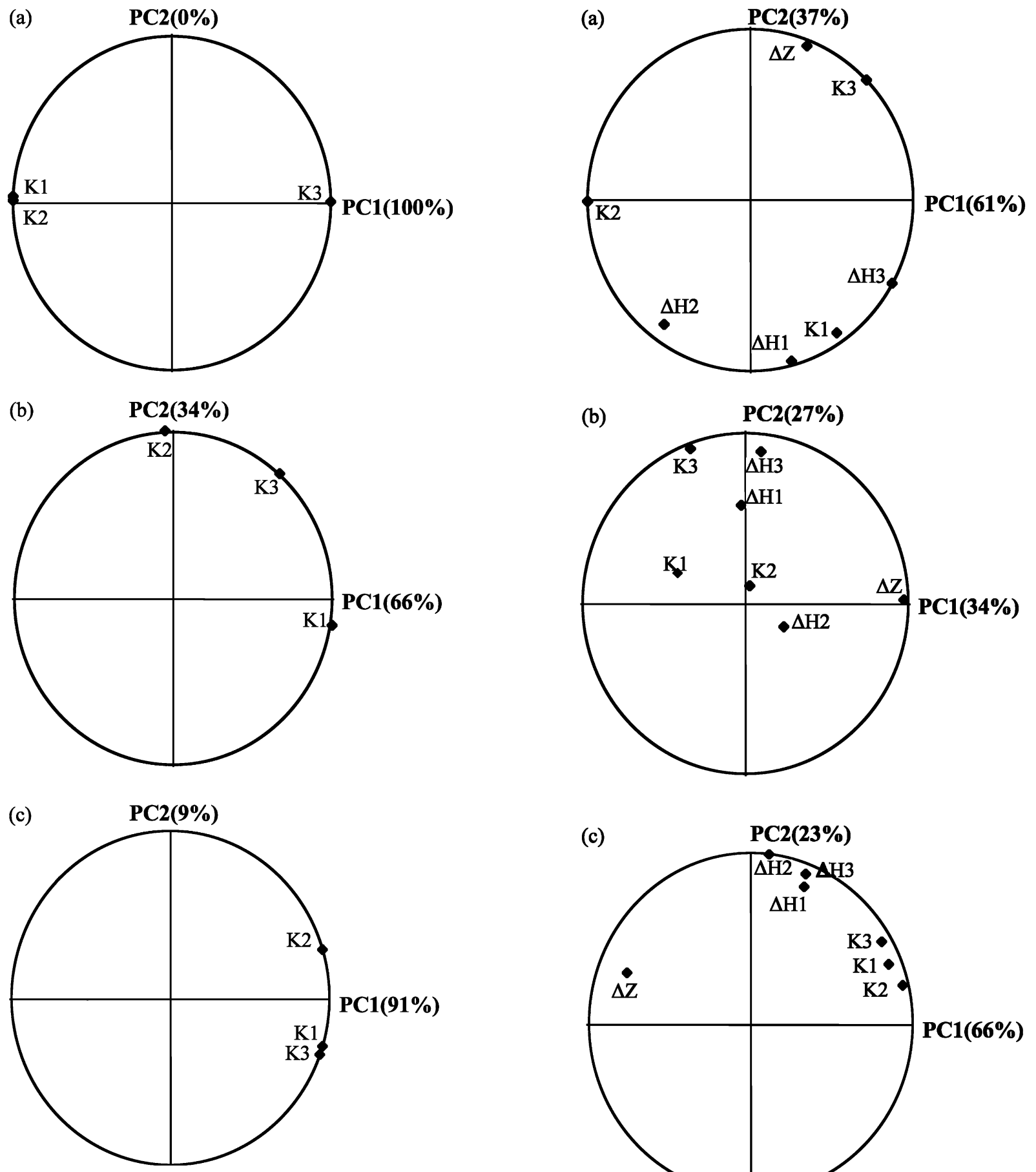

Fig. 9a-c

Correlation circles of Dataset \#1 at (a) micro scale, (b) local scale and (c) regional scale

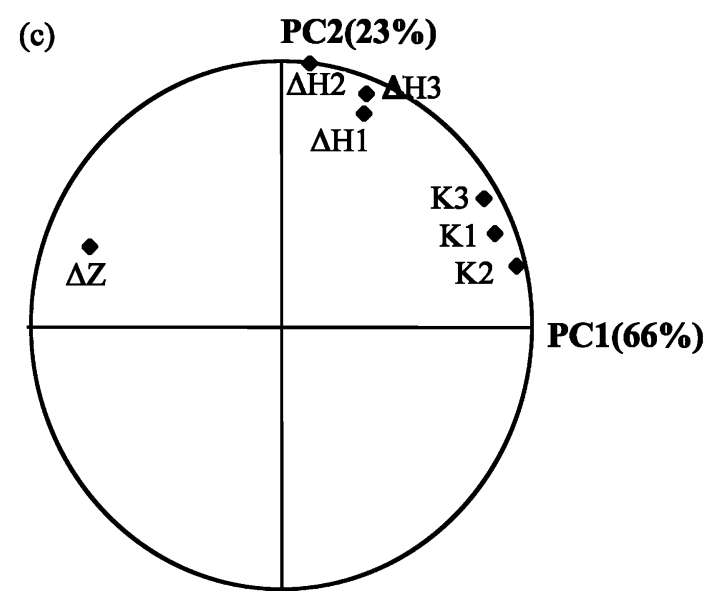

Fig. 10a-c

Correlation circles of Dataset \#2 at (a) micro scale, (b) local scale and (c) regional scale

The interface between the gravels and the sands in the aquifer serves as a pipe-reducer, causing the groundwater level to rise suddenly. The model (Lin and others 2004) explains not only that $\mathrm{K}$ (not $\Delta \mathrm{Z}$ ) affects $\Delta \mathrm{H}$ but also why $\Delta \mathrm{H} 2, \mathrm{~K} 1$ and $\mathrm{K} 2$ are clustered in the correlation circle (Fig. 10b). Based on deterministic model fitting, a vertical flow occurs from Aquifer 2 to Aquifer 1 in the ChouShui River alluvial fan, causing severe sand boiling. The vertical flow connects $\Delta \mathrm{H} 2$ not only to $\mathrm{K} 2$ but also to $\mathrm{K} 1$ at

local scale as relationship $\Delta \mathrm{H} 3-\mathrm{K} 3-\mathrm{K} 2$ at micro scale. Restated, the hydraulic conductivity of Aquifer 2 and the hydraulic conductivity of Aquifer 1 that overlaps Aquifer 2 affect changes in the level of groundwater in Aquifer 2. At regional scale, the relationships $\Delta \mathrm{Z}-\mathrm{K} 1, \Delta \mathrm{Z}-\mathrm{K} 2$ and $\Delta \mathrm{Z}-\mathrm{K} 3$ can be distinguished from $\mathrm{PC} 1$, as shown in Fig. 10c. $\Delta \mathrm{H} 1, \Delta \mathrm{H} 2$ and $\Delta \mathrm{H} 3$ are closely aligned on the positive side of PC2, as shown in Fig. 10c. The vertical 
displacement of the ground in the ChouShui River alluvial fan, $\Delta \mathrm{Z}$, is the sum of the faulting displacement, the crust deformation and the alluvium consolidation. The consolidation of the soil skeleton is governed by the hydraulic conductivity as an independent variable; hence a fraction of $\Delta \mathrm{Z}$ should be related to the alluvium consolidation at regional scale. A factor other than the alluvium consolidation is responsible for $\Delta \mathrm{H} 1, \Delta \mathrm{H} 2$ and $\Delta \mathrm{H} 3$. Wang and others (2001) suggested that the cyclic loading of deviatoric stress generates changes in the groundwater level. The bearing energy per unit area of land is inversely proportional to the square of the traveling distance of the wave (Lay $T$ and Wallace TC 1995). This relationship is used to explain how relocating the sedimentary particles reduce the porosity when the loading intensity is below a threshold, and yields high pore pressure. However, the loading intensity exceeds the threshold, the porosity increases because the interlocking among the particles is destroyed and the soil skeleton is expanded.

\section{Mapping regionalized factors}

\section{Dataset \#1}

Figure 11 maps the regionalized factors PC1 and PC2 of Dataset \#1. At a regional scale (Fig. 11a and b), the result supports the PCA result. Figure 11a presents an area of high spatial variation in the central part of the study area, where $\mathrm{K} 1, \mathrm{~K} 2$ and $\mathrm{K} 3$ dominate the variation in the distribution governed by the ChouShui River, which flows from east to west; Fig. 11b shows the high variation in the northwestern and southern parts of the study area, demonstrating the effect of the rising and falling of the global mean sea level. The directions of influence of the driving

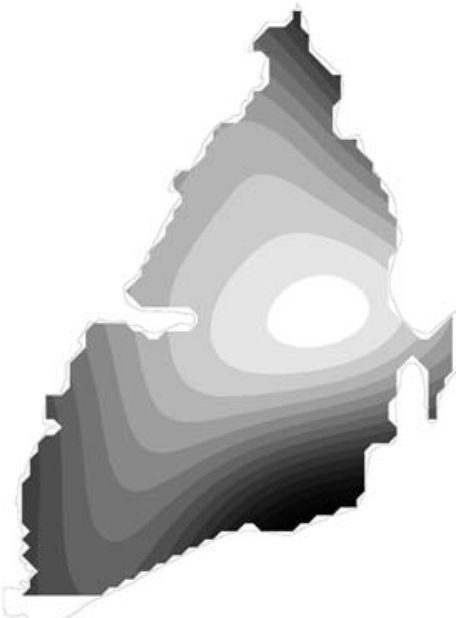

(a)

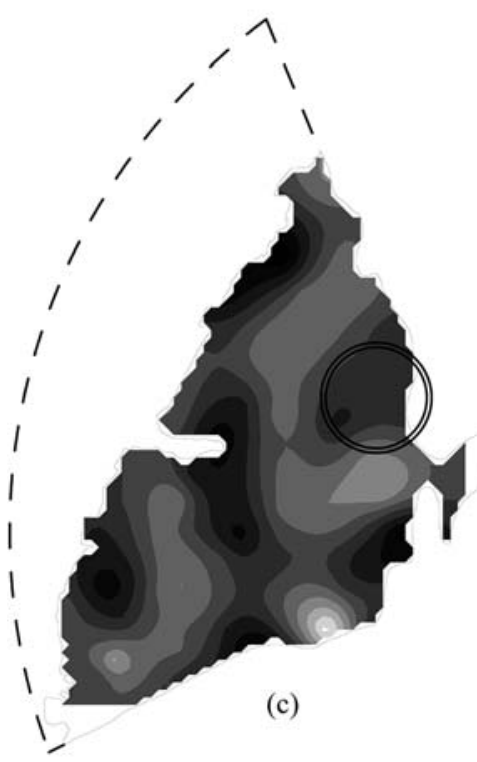

The pinch-out of the aquifer
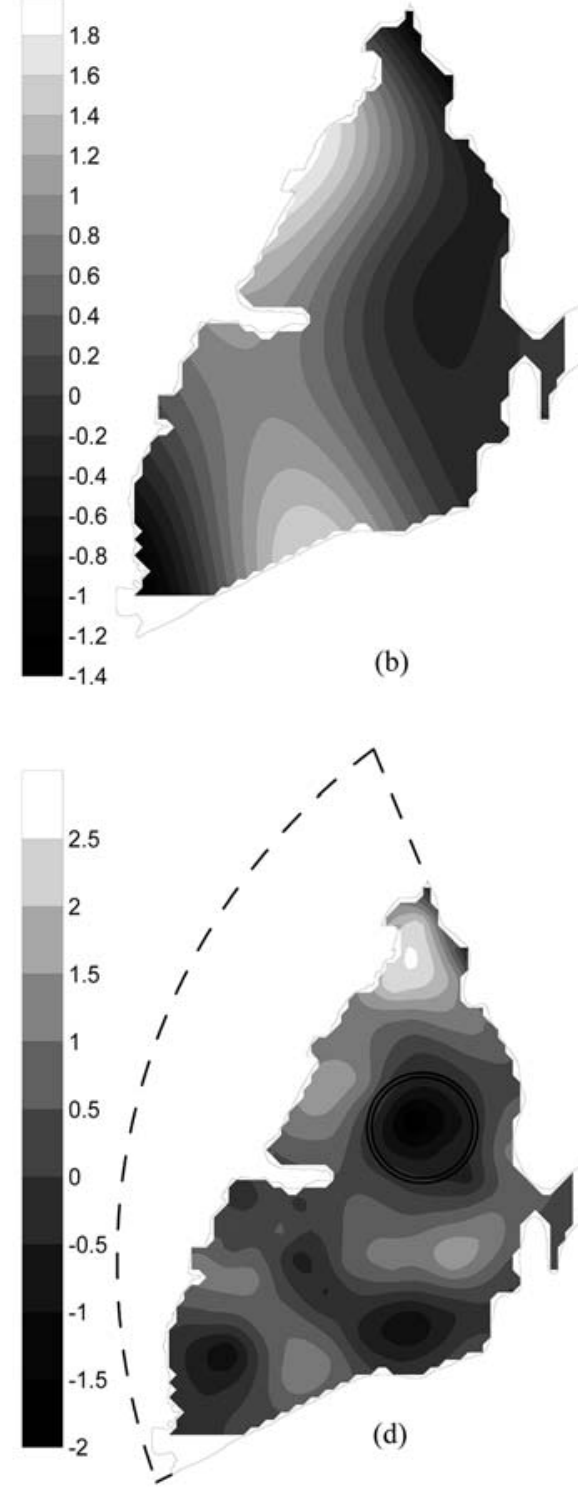

encircled pinnacle

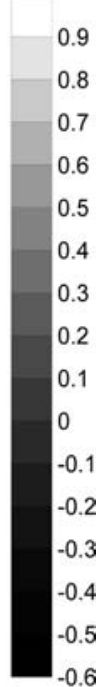

Fig. 11a-d

Mappings of regionalized factors of (a) PC1 at regional scale, (b) PC2 at regional scale, (c) PC1 at local scale and (d) PC2 s at local scale, for Dataset \#1 
force, concerning the sedimentary distribution, indicated by $\mathrm{PC} 1$ and $\mathrm{PC} 2$, are perpendicular to each other, as shown in Fig. 11a and b. At local scale (Fig. 11c and d), the spatial variation is distributed in ripples that encircle the pinnacle of the fan. The ripples have a similar shape to the pinch-out of the aquifer. The directions that influence the driving force, indicated by PC1 and PC2, are aligned. Figure 11c presents the spatial variation of $\mathrm{PC} 1$, dominated by K1 variations; Fig. 11d presents the spatial variation of $\mathrm{PC} 2$, dominated by $\mathrm{K} 2$ variations, according to the PCA result at local scale. The notable difference between the figures is that the encircled pinnacle is west in Aquifer 2 but east in Aquifer 1, as shown in Fig. 11c and $\mathrm{d}$, and marked with double circles. Aquifer 1 thus exhibited the highest mean sea level when it was formed; Aquifer 2 exhibited the lowest, and Aquifer 3 had a middling sea level. The causes of the rippling distribution will be discussed below.

\section{Dataset \#2}

Figure 12 maps the regionalized factors PC1 and PC2 of Dataset \#2. At regional scale (Fig. $12 \mathrm{a}$ and $\mathrm{b}$ ), $\Delta \mathrm{Z}$ and $\mathrm{K}$ dominate the spatial variation of PC1 after the ChiChi earthquake (Fig. 12a). Figure 12a implies that the area of high spatial variation is elongated from the north to the southwest of the ChouShui River basin. Unlike in Fig. 11a, which plots the spatial variation of $\mathrm{K}$ before the ChiChi earthquake, the earthquake may rotate the hydrogeological characteristics at regional scale, generating a rotational displacement field in the northern part of the fan and a counter-clockwise rotation of the variation in hydraulic conductivity after the earthquake. This PCA result verifies the report of Huang (2003) that indicates that the ground is rotated by the bending of the fault at the northern end of the CheLungPu Fault. A further study of the earthquakeinduced variation of hydraulic conductivities should concentrate on the northern part of the fan in the study area.
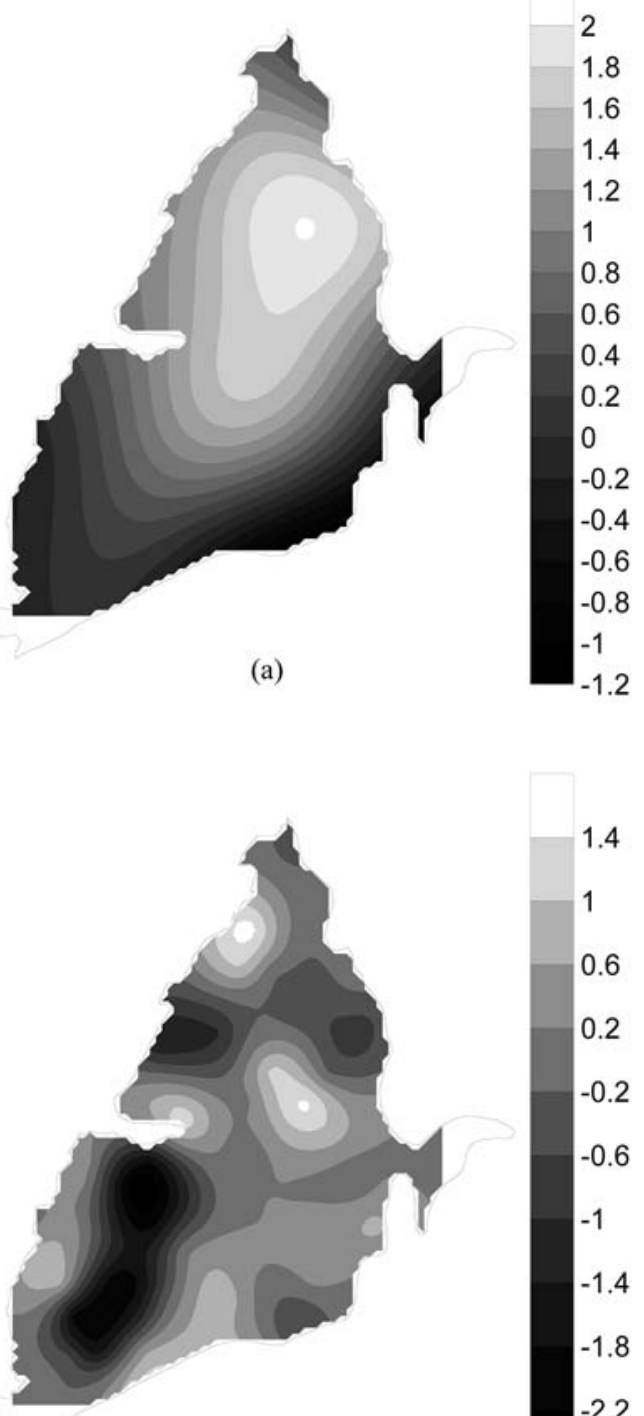

(c)
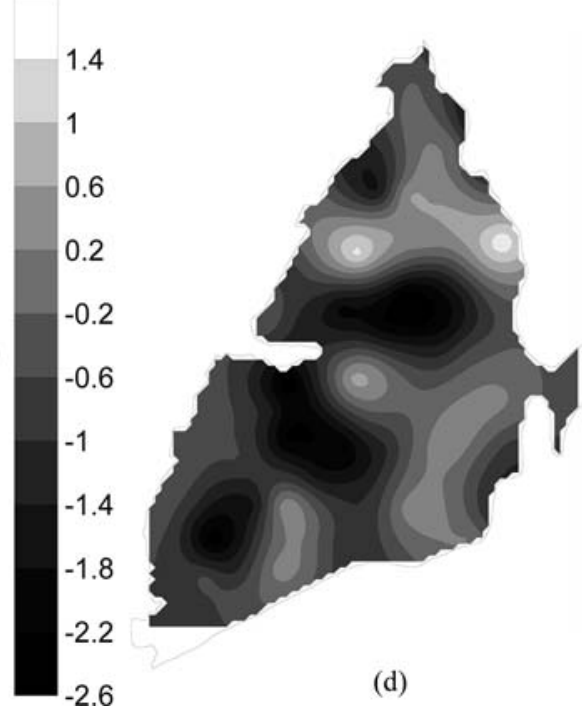
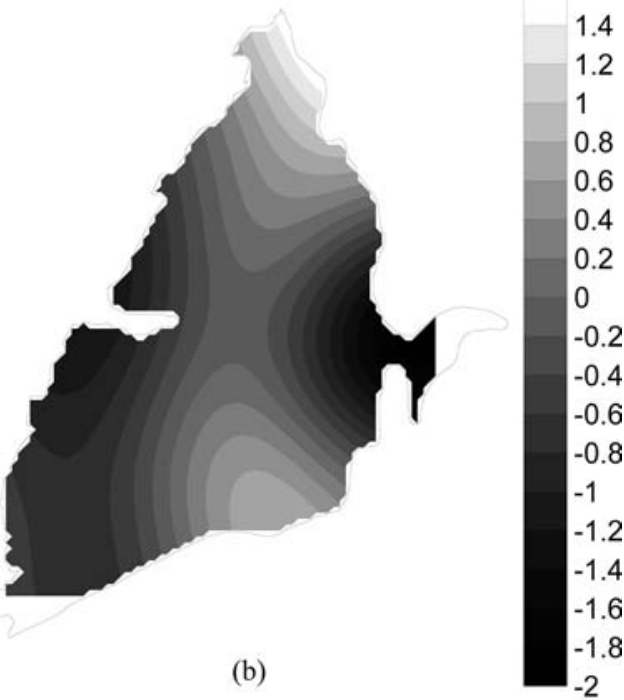

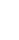


At regional scale, the areas of $\mathrm{H}$ with high variation in all aquifers, which dominate $\mathrm{PC} 2$, are in the northern and southern parts of the study area, as shown in Fig. 12b. The spatial anomalous variation shows that the groundwater level rises from the east toward the middle of the fan and then falls toward the west. The PCA result of Dataset \#2 at regional scale also demonstrates that changes in the groundwater level interact weakly with $\Delta \mathrm{Z}$ and the hydraulic conductivity of the aquifer. Both PCA and mapping results verify the conclusion of Wang and others (2001), that the cyclic loading of deviatoric stress causes the large change in the level of groundwater in the middle of the fan.

At local scale, $\Delta \mathrm{Z}$ dominates PC1. Figure $12 \mathrm{c}$ plots the spatial variation of $\mathrm{PC} 1$ governed by $\Delta \mathrm{Z}$. As indicated in Table 2, the correlation coefficient between the vertical displacements of the ground and the soil parents is the largest. A comparison with the map of the distribution of the parent soils (Fig. 3a) shows that the distribution of the large vertical displacements of the ground at local scale is consistent with the distribution of the mixture of mudstone and slate in the southwest of the fan. Hence, the vertical displacements at local scale may be correlated with the shaking of the ground that induces the alluvial consolidation. Figure12d plots the spatial variation of PC2 dominated by $\Delta \mathrm{H} 3$ and $\mathrm{K} 3$ at local scale, representing interactions among the hydrogeological properties. The rippling distribution of the hydraulic conductivity was formed in the interglacial period. In the glacial period, the ability of the river to transport sediment is poor because of the arid climate, which is responsible for the formation of the very steep pile of sediments upstream. Then, in the interglacial period, the more powerful transport of the river erodes the pile and carries erosion further downstream. The downstream sediments form a looser stack than the upstream sediments and are responsible for the rippling distribution of the hydraulic conductivity (Chang 1997).

\section{Conclusions}

This study for the first time analyzes a completely heterotopic dataset. Three methods of treating data with various associated uncertainty were conducted to relocate the dataset without destroying the spatial structure of the original dataset. The SGS method was selected because the local heterogeneity of the variables in the study area was high. Sufficient evenly distributed field data provided a great opportunity to analyze statistically the scale-dependent causes of the hydrogeological changes in the ChouShui alluvial fan caused by the ChiChi earthquake. In factorial kriging analysis, three scales presented in this study fit the experimental semivariograms well and indicate various causes of the hydrogeological changes induced by the earthquake. The results show that the earthquake may have rotated the ground, altering the hydraulic conductivities on the northern fan at regional scale. The vertical flow from Aquifer 2 to Aquifer 1 is more heterogeneous than that from Aquifer 3 to Aquifer 2. The results also show that the porous media compressions contribute $12 \%$ of the variation of the groundwater levels, over a distance of influence of $9 \mathrm{~km}$, the hydrogeological heterogeneity of the sediments within the aquifer contributes $37 \%$, over a distance of influence of $12 \mathrm{~km}$ and the cyclic loading of deviatoric stress contributes $51 \%$ over a distance of influence of $36 \mathrm{~km}$. Variations at regional scale dominated the total variations. FKA was used to map regionalized factors at micro, local and regional scales, anomalous spatial variations of hydrogeological properties before and after the ChiChi earthquake in the study area were fully demonstrated. Finally, the maps of spatial variation at each spatial scale could be used further to support the hydrogeological monitoring and surveying of the study area.

Acknowledgement The authors would like to thank the National Science Council of Taiwan for financially supporting this research under Contract No. NSC 90-2625-Z-002-025. The authors also extend their gratitude to the Council of Agriculture, Department of Land Administration, Water Resources Agency and Central Geological Survey of TAIWAN for providing the field data.

\section{References}

Almeida A, Journel A (1994) Joint simulation of multiple variables with Markov-type coregionalization model. Math Geol 26:565-588

Anderson TW (1984) An introduction to multivariate statistical analysis. Wiley, New York

Biot MA (1956a) Theory of propagation of elastic waves in a fluidsaturated porous solid, I. low-frequency range. The Journal of the Acoustical Society of America 28:168-178

Biot MA (1956b) Theory of propagation of elastic waves in a fluid-saturated porous solid, II. High-frequency range. The Journal of the Acoustical Society of America 28:179-191

Castrignanò A, Giugliarini L, Risaliti R, Martinelli N (2000) Study of spatial relationships among some soil physica-chemical properties of a field in central Italy using multivariate geostatistics. Geoderma 97:39-60

Central Geological Survey (1994) The final survey report of the ChouShui alluvial fan. Ministry of Economic Affairs, Taiwan (in Chinese)

Central Geological Survey (1999) The hydrogeological survey report of the ChouShui alluvial fan. Ministry of Economic Affairs, Taiwan (in Chinese)

Chang JC (1997) Distribution, morphology and geomorphic implication of the alluvial fans in Taiwan. Geology 17:69-93 (in Chinese)

Chia YP, Wang YS, Chiu JJ, Liu CW (2001) Changes of groundwater level due to the 1999 ChiChi earthquake in the ChouShui River alluvial fan in Taiwan. Bulletin of the Seismological Society of America 91:1062-1068

Chilès JP, Delfiner P (1999) Geostatistics: modeling spatial uncertainty. Wiley, New York

Christakos G (1984) On the problem of permissible covariance and variogram models. Water Resour Res 20:251-265

Cooper HH, Bredehoeft DJ, Papadopulos IS, Bennett RR (1965) The response of well aquifer systems to seismic waves. J Geophys Res 70:3915-3926

Council of Agriculture (1997) Soil map of cultivated lands. Executive Yuan, Taiwan (digital data) 
Cressie N (1990) The origins of kriging. Math Geol 22:239-252 Department of Land Administration (2000) The records of the first and the second class standardized satellite oriented control points. Ministry of the Interior, Taiwan (digital records)

Deutsch CV, Cockerham PW (1994) Practical considerations in the application of simulated annealing to stochastic simulation. Math Geol 26:67-82

Deutsch CV, Journel AG (1998) GSLIB: Geostatistical software library and user's guide. Oxford University Press, New York

Freeze RA (1975) A stochastic-conceptual analysis of onedimension groundwater flow in non-uniform homogeneous media. Water Resour Res 11:725-741

Goovaerts P (1997) Geostatistics for natural resources evaluation. Oxford University Press, New York

Goovaerts P, Webster M (1994) Scale dependent correlation between topsoil copper and cobalt concentrations in Scotland. European Journal of Soil Science 45:79-95

Goulard M (1989) Inference in coregionalization model. In: Armstrong M (eds) Geostatistics. Kluwer, Dordrecht, Vol. 1, pp 397-408

Goulard M, Voltz M (1992) Linear coregionalization model: tools for estimation and choice of cross-variogram matrix. Math Geol 24:269-286

Grecksch G, Roth F, Kumpel HJ (1999) Coseismic well level changes due to 1992 Roermond earthquake comparing to static deformation of half space solutions. Geophys J Int 138:470-478 Hsu SK (1998) Plan for a groundwater monitoring network in Taiwan. Hydrogeology J 6:405-415

Huang BS (2000) Two dimensional reconstruction of the surface ground motion of an earthquake: the September 21, 1999, ChiChi, Taiwan earthquake. Geophys Res Lett 27:30253028

Huang BS (2003) Ground rotational motions of the 1999 Chi-Chi, Taiwan earthquake as inferred from dense array observations. Geophys Res Lett 30: Art. No. 1307

Isaak EH, Srivastava RM (1989) An introduction to applied geostatistics. Oxford University Press, New York

Korner TW (1988) Fourier analysis. Cambridge University Press, New York

Kunugi T, Fukao Y, Ohno M (2000) Underdamped responses of a well to nearby swarm earthquakes off the coast of Ito City, central Japan, 1995. J Geophys Res-Solid Earth 105(B4):78057818

Lay T, Wallace TC (1995) Modern global seismology. Academic Press, San Diego

Lee M, Liu TK, Ma KF, Chang YM (2002) Cosiesmic hydrological changes associated with dislocation of the September 21, 1999 Chichi earthquake, Taiwan. Geophys Res Lett 29: Art. No. 1824

Lin YB, Tan YC, Yeh TCJ, Liu CW, Chen CH (2004) A Viscoelastic model for groundwater level changes in ChouShui river alluvial fan after the ChiChi earthquake in Taiwan. Water Resour Res 40:W04213

Lin YP (2002) Multivariate geostatistical methods to identify and map spatial variations of soil heavy metals. Environ Geol 42:1-10

Lin YP, Chang TK (2000) Simulated annealing and kriging method for identifying spatial patterns and variability of soil heavy metal. J Environ Sci Health A37:1089-1115

Lin YP, Chang TK, Teng TP (2000a) Characterization of soil lead by comparing sequential Gaussian simulation, simulated annealing simulation and kriging methods. Environ Geol 41:189-199
Lin YP, Lee CC, Tan YC (2000b) Geostatistical approach for identification of transmissivity structure at Dulliu area in Taiwan. Environ Geol 40:111-120

Lin YP, Tan YC, Rouhani S (2001) Identifying spatial characteristics of transmissivity using simulated annealing and kriging methods. Environ Geol 41:200-208

Ma KF, Lee CT, Tsai TB (1999) The ChiChi, Taiwan earthquake: large surface displacement on an inland thrust fault. Eos (Transactions, Am Geophysical Union) 80:605-611

Ma KF, Mori J, Lee SJ, Yu SB (2001) Spatial and temporal distribution of slip for the 1999 ChiChi, Taiwan, earthquake. Bulletin of the Seismological Society of America 91:1069-1087

Matheron G (1989) Estimating and choosing. Springer, Berlin Heidelberg New York

Montgomery DR, Manga M (2003) Streamflow and water well responses to earthquakes. Science 300:2047-2049

Odeh IOA, Mcbratney AB, Chittleborough DJ (1995) Further results of soil properties from terrain attributes: heterotopic cokriging and regression -kriging. Geoderma 67:215-226

Ohno M, Wakita H (1997) A water well sensitive to seismic waves. Geophys Res Lett 24:691-694

Roeloffs EA (1996) Poroelastic techniques in the study of earthquake-related hydrologic phenomena. In: Dmowska R, Saltzman B (eds) Advances in Geophysics. Academic Press, New York, Vol. 37, pp 135-195

Roeloffs EA (1998) Persistent water level changes in a well near ParkField, California, due to local and distant earthquake. J Geophys Res 103:869-889

Sandjivy L (1984) The factorial kriging analysis of regionalized data. In: Verly G, David M, Journel AG, Marechal A (eds) Geostatistics for Natural Resources Characterization. Reidel, Dordrecht, pp 559-571

Taiwan Sugar Corporation (1997) Establishment and operational management of Groundwater Monitoring Network. Water Resources Agency, Taiwan

Wackernagel H (1988) Geostatistical techniques for interpreting multivariate spatial information. In: Chung CF, Fabbri AG, Sinding-Larsen R (eds) Quantitative Analysis of Mineral and Energy Resources. Reidel, Dordrecht, pp 393-409

Wackernagel H (1994) Cokriging versus kriging in regionalized multivariate data analysis. Geoderma 62:83-92

Wackernagel H (1995) Multivariate geostatistics: an introduction with applications. Springer, Berlin Heidelberg New York

Wackernagel H, Petitgas P, Tauffait Y (1989) Overview of methods for coregionalization analysis. In: Armstrong M (eds) Geostatistics. Kluwer, Dordrecht, Vol. 1, pp 409-420

Wang CY, Cheng LH, Chin CV, Yu SB (2001) Coseismic hydrologic response of an alluvial fan to the 1999 ChiChi earthquake, Taiwan. Geology 29:831-834

Water Resources Agency (1999a) The annual report of the Groundwater Monitoring Network System (GMNS) records in Taiwan. Ministry of Economic Affairs, Taiwan (in Chinese) Water Resources Agency (1999b) The compilation of the results of the Taiwan groundwater monitoring network plan (first period). Ministry of Economic Affairs, Taiwan (in Chinese) Woodbury AD, Sudicky EA (1991) The geostatistical characteristics of the Borden aquifer. Water Resour Res 27:533-546 Yu SB, Kuo LC, Hsu YJ, Su HH, Liu CC, Hou CS, Lee JF, Lai TC, Liu CC, Liu CL, Tseng TF, Tsai CS, Shin TC (2001) Preseismic deformation and coseismic displacement associated with the ChiChi, Taiwan, earthquake. Bulletin of the Seismological Society of America 91:995-1012

Yvan P (1996) Variowin. Springer, Berlin Heidelberg New York 